\title{
Pancreatic cancer-derived exosomes promote tumor metastasis and liver pre-metastatic niche formation
}

\author{
Zeqian Yu' ${ }^{1,2}$, Susu Zhao ${ }^{3}$, Long Ren ${ }^{1}$, Lishan Wang ${ }^{1}$, Zhangjun Chen ${ }^{1,2}$, Robert M. \\ Hoffman ${ }^{4,5}$ and Jiahua Zhou ${ }^{1,2}$ \\ ${ }^{1}$ Department of Hepatic-Biliary-Pancreatic Center, Zhongda Hospital, Southeast University, Nanjing, China \\ ${ }^{2}$ Department of Hepatobiliary Surgery Research Institute, Southeast University, Nanjing, China \\ ${ }^{3}$ Department of Pathology, Traditional Chinese Medicine Hospital of Jiangsu Province, Nanjing, China \\ ${ }^{4}$ Department of Surgery, University of California at San Diego, San Diego, California, USA \\ ${ }^{5}$ AntiCancer, Inc., San Diego, California, USA \\ Correspondence to: Jiahua Zhou, email: zhoujh@seu.edu.cn
}

Keywords: pancreatic cancer, exosomes, pre-metastatic niche, proteomics, iTRAQ

Received: March 31, $2017 \quad$ Accepted: June 01, $2017 \quad$ Published: June 28, 2017

Copyright: Yu et al. This is an open-access article distributed under the terms of the Creative Commons Attribution License 3.0 (CC BY 3.0), which permits unrestricted use, distribution, and reproduction in any medium, provided the original author and source are credited.

\section{ABSTRACT}

Exosomes play important roles in cell-cell communication, and are likely mediators of the metastatic cascade in cancer. This study examined the role of exosomes in pancreatic cancer cell adhesion, migration, and invasion. We isolated and purified exosomes from two isogenic pancreatic cancer cell lines with different metastatic potentials. Uptake of exosomes from highly metastatic Panc02-H7 cells decreased adhesion and increased migration and invasion capacity in weakly metastatic Panc02 cells in vitro. Exosomes from highly metastatic pancreatic cancer cells induced liver pre-metastatic niche formation in naïve mice and promoted primary tumor growth and liver metastasis in vivo. We identified 4,517 proteins in exosomes from Panc02 and Panc02-H7 cells via iTRAQ quantitative proteomic analyses, 79 of which were differentially expressed between the two cell lines. Bioinformatics analyses showed that most of the differentially expressed proteins were involved in pancreatic cancer growth, invasion, and metastasis, and that metabolism-related signaling pathways were involved in exosome-mediated intracellular communication. Further studies will be needed to determine whether these proteins are potential pancreatic cancer diagnostic/prognostic markers or novel therapeutic targets.

\section{INTRODUCTION}

Pancreatic ductal adenocarcinoma (PDAC) is one of the most aggressive human malignancies, and is one of the five most common causes of cancer mortality world wide. An estimated 53,070 new pancreatic cancer cases will be diagnosed and 41,7800 patients will die from pancreatic cancer in the United States in 2017 [1]. Rising incidence and mortality rates were also observed in 2015 in China [2]. Despite some progress in surgical techniques, chemotherapy, and radiotherapy, pancreatic cancer patient prognosis is extremely poor, with an overall
5 -year survival rate $<6 \%$. Median survival is $8-12$ months for patients with locally advanced disease, and only 3-6 months for those with metastatic disease [3]. Accurate diagnostic biomarkers to detect pancreatic cancer at an earlier stage, and novel therapeutic strategies that target metastatic disease are urgently needed to improve patient outcomes.

The tumor microenvironment comprises cancer and stromal cells, along with extracellular matrix (ECM) components and secreted soluble factors, such as chemokines, cytokines, and growth factors. These soluble factors facilitate cell-cell communication, tumor 
progression and metastasis, and pre-metastatic niche generation in distant organs. Recent studies identified tumor-derived exosomes as key modulators of the tumor microenvironment that mediate cell-cell communication and eventually induce metastatic niche formation [4].

Exosomes are 40-100 nm diameter vesicles derived from late endosome/multivesicular body (MVB) luminal membranes, and are constitutively released via fusion of MVBs with the cell membrane under both physiological and pathological conditions. Exosomes are enriched in parent cell-derived bioactive molecules, including proteins, RNAs, and lipids, which can be horizontally transferred to recipient cells and regulate their function [5]. Specific proteins have been identified in PDAC exosomes [6-10], but a comparative proteomics analysis of exosomes secreted by PDAC cell lines of different metastatic potential has not been performed. The present study used iTRAQ-quantitative proteomic analysis to identify the protein compositions of exosomes derived from two isogenic PDAC cell lines, Panc02 and Panc02-H7, which differ in their degree of metastatic potential [11]. We identified potential key proteins that facilitate crosstalk between the primary tumor and the microenvironment, and which may be useful biomarkers for PDAC diagnosis and prognosis.

\section{RESULTS}

\section{Panc02 EXO and Panc02-H7 EXO characterization}

Purified exosomes were isolated using ultracentrifugation combined with sucrose density gradient centrifugation (Figure 1A). Western blotting confirmed the presence of several classical common exosome markers, including TSG101, CD9, and MHC-I (Figure 1B). Cytochrome c, a mitochondrial marker, was detected in two whole cell lysates, but was absent from exosomes, indicating that the exosomes were not contaminated with other vesicles (Figure 1B). Sizes and morphological characteristics of exosomes derived from two pancreatic cancer cell lines were assessed via transmission electron microscopy (TEM). Exosomes from both cell lines were cup-shaped and ranged from 50-150 $\mathrm{nm}$ in diameter (Figure 1C). Exosomes from the highly metastatic pancreatic cancer cell line (Panc02-H7 EXO) expressed more total protein than exosomes from the poorly metastatic cell line (Panc02 EXO) (Figure 1D).

\section{Panc02-H7-derived exosomes decreased adhesion and increased migration and invasion in recipient cells}

We incubated PKH67-labeled Panc02-H7 EXOs with Panc02 cells. After five h, numerous green fluorescent exosomes were observed inside Panc02 cells via fluorescence microscopy. Exosomes were mainly located at the perinuclear region, suggesting Panc 02 cell uptake of Panc02-H7 EXOs (Figure 2A). We speculated that exosome cargo release might affect recipient cell metastatic capabilities. Therefore, we analyzed recipient cell adhesive, migratory, and invasive potential following exosome internalization. Amiloride reportedly depresses cell exosome secretion [12]. In the MTT cell adhesion assay, Panc02 cells exposed to PBS (control group), $100 \mu \mathrm{g} / \mathrm{ml}$ Panc02-H7 EXOs (EXO group), or $7 \mathrm{mmol} /$ Lamiloride (Exo-D group) for $24 \mathrm{~h}$ were inoculated into 96-well plates in serum-free medium. Cell attachment was greater in the Exo-D group than in the EXO and control groups (Figure 2B), indicating that Panc02-H7 EXOs may decrease Panc02 cell adhesion. In a woundhealing assay, migration was increased in the EXO group compared to the control and Exo-D groups (Figure 2C). Similarly, transwell chamber invasion assays results showed increased invasion by EXO group cells compared to control and Exo-D cells (Figure 2D). Western blotting results showed that CXCR4 and MMP-9 levels were higher in the EXO group than in the control group, but were reduced in the Exo-D group (Figure 2E). These results suggest that exosomes from high metastaticpotential cells can induce metastatic behavior in Panc02 cells.

\section{Exosome tissue distribution and liver pre-metastatic niche formation}

Exosome biodistribution in liver, lung, spleen, kidney, brain, and bone marrow was assessed $24 \mathrm{~h}$ postinjection (hpi) of exosomes using confocal microscopic analysis. Pancreatic cancer-derived exosomes accumulated in the lung, liver, and spleen, with less accumulation in the brain and bone marrow compared to a liposome control (Figure 3A). Panc02-H7 cell-derived exosomes accumulated at higher levels in the lung, liver, and bone marrow than exosomes from Panc02 cells (Figure 3A).

Immunofluorescence (IF) quantitative analysis showed that Panc02-H7 EXOs increased the frequency of $\mathrm{CD}_{11} \mathrm{~b}^{+}$(also confirmed by Western blotting) and CD45 ${ }^{+}$ hematopoietic progenitor cells at pre-metastatic sites after 12 d compared with Panc02 EXO and control groups (Figure 3B). Pancreatic cancer-derived exosomes also induced Stat 3 activation and myeloid infiltration (over 12 $\mathrm{d}$ of treatment). Stat3 activity was detectable in myeloid cells and in the liver (Figure 3B). We observed increased alpha smooth muscle actin $(\alpha-\mathrm{SMA})^{+}$hepatic stellate cells (hStCs) and fibronectin (FN) upregulation in mice treated with Panc02-H7 EXOs compared with Panc02 EXOs and controls. We found a predominant $\alpha-\mathrm{SMA}^{+}$ cell population in FN-enriched liver areas in mice treated with Panc02-H7 EXOs, suggesting that activated hStCs produced most of the FN (Figure 3C). Western blotting analysis showed upregulated S100A8 and S100A9 in 
Panc02-H7 EXO-treated livers (Figure 3D).Panc02-H7 EXOs increased myeloid-derived suppressor cell (MDSC) $\left(\mathrm{CD} 11 \mathrm{~b}^{+} \mathrm{GR} 1^{+}\right.$cell $)$frequency in peripheral blood more than Panc02 EXOs and the control group (Figure 3E).

\section{Tumor-derived exosomes promote pancreatic cancer growth, micrometastasis, and metastasis}

We administed Panc02-H7 EXOs and Panc02 EXOs $(10 \mu \mathrm{g})$ intravenously (tail vein) into C57B/L6 mice three $d$ per week, starting seven d after pancreatic cancer surgical orthotopic implantation (SOI). Primary tumor volume only increased at $30 \mathrm{~d}$ post-SOI (Figure 4B). In contrast to controls, only Panc02-H7 EXO-treated mice exhibited lung and liver micrometastasis at d 15 (Figure 4C). These mice also had a greater metastatic burden and cancer cell distribution in the liver, lung, diaphragm, pleura, adrenal gland, small intestine, lymph nodes, and spleen compared to PBS- or Panc02 EXO-treated mice (Figure 4A). These data suggest that qualitative exosome content differences can mediate metastatic potential and organ otropism.

S100A8 and S100A9 were upregulated, and F4/80 $0^{+}$macrophages, $\alpha-\mathrm{SMA}^{+} \mathrm{hStCs}$, and neutrophils were increased in Panc02-H7 EXO-treated mouse livers compared with untreated, Panc02 EXO-, or PBStreated livers (Figure 5A-5B \& 5C-5E). There was no difference between the Panc02 EXO and control groups. Immunohistochemical (IHC) analyses and Masson's trichrome staining showed that FN was upregulated in Panc02-H7 EXO-treated mouse livers. Connective tissue deposition was increased in mouse livers treated with either type of exosome compared with control and normal liver, with no difference between the two exosomes
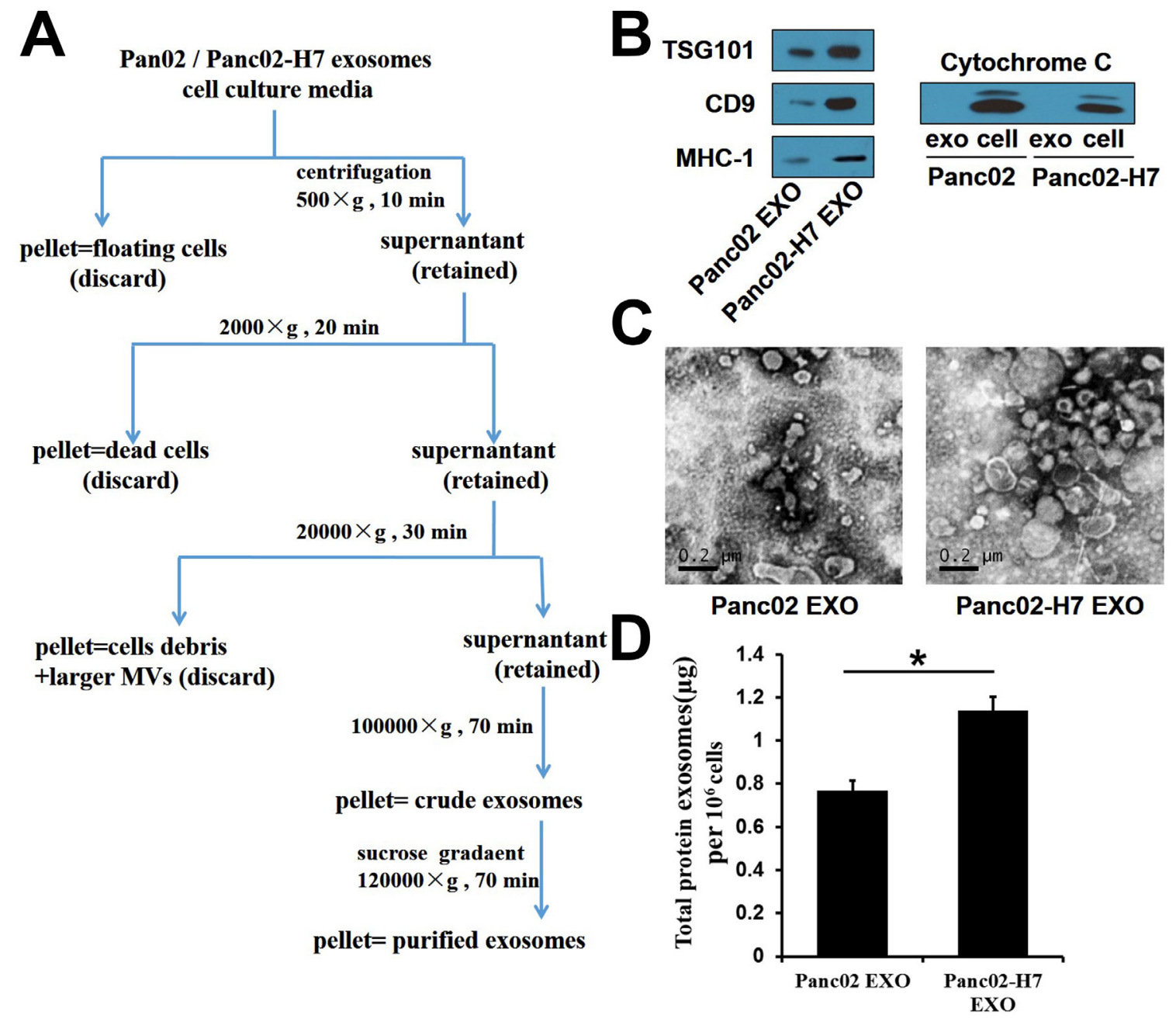

Figure 1: Characterization of Panc02- and Panc02-H7-derived exosomes. Exosome isolation and purification schematic (A) Common exosome markers, including TSG101, CD9, and MHC-I, were detected in two exosomes (B) Cytochrome c was detectable in two whole-cell lysates, but not in exosomes. Panc02 EXOs and Panc02-H7 EXOs were negatively stained with 3\%phosphotungstic acid and viewed by TEM (scale bar $=200 \mathrm{~nm}$ ) (C) Total protein per million cells in two exosomes (D) Panc02-H7EXOs expressed more total protein than Panc02 EXOs. $(* \mathrm{P}<0.05)$. 
(Figure 5C-5D). These data suggest that pancreatic cancer-derived exosomes may reprogram the liver to form liver metastatic niches.

\section{Exosomal protein identification via iTRAQ- based proteomic analysis}

Ultimately, 65,077 unique spectra, 22,912 unique peptides, and 4,517 proteins were identified via iTRAQbased proteomic analysis in the two types of pancreatic cancer exosomes, $71.09 \%$ of which were identified with $\geq 2$ peptide matches (Supplementary Table 1). The 4,517 common exosome proteins were classified into three groups, cellular components, molecular function, and biological process, through Blast2go to assess gene ontology (GO) enrichment (Figure 6). Based on different molecular functions, these proteins were grouped as follows: binding, catalytic activity, enzyme regulator activity, transporter activity, structural molecule activity, and transcription factors. The common exosomal proteins are mainly involved in metabolic, structural, and regulating processes. Table 1 shows the top 25 pathways involving these proteins.

\section{Bioinformatic analysis of proteins differentially expressed between high- and low-metastatic exosomes}

79 proteins were differentially expressed between high- and low-metastatic exosomes (Table 2). We again performed a Blast2go analysis to assess protein gene ontology (GO) enrichment (Figure 7).

\section{Validation of differentially expressed proteins identified by iTRAQ quantitative proteomics}

We validated six candidate proteins using Western blotting.SBP1, CKAP4, and ALDOC were downregulated, and FAR2, IGF2BP1, and S100A11 were upregulated in Panc02-H7 EXOs compared to Panc02EXOs (Figure
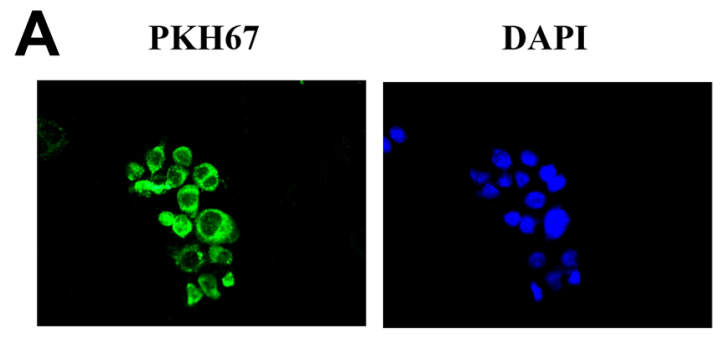

C

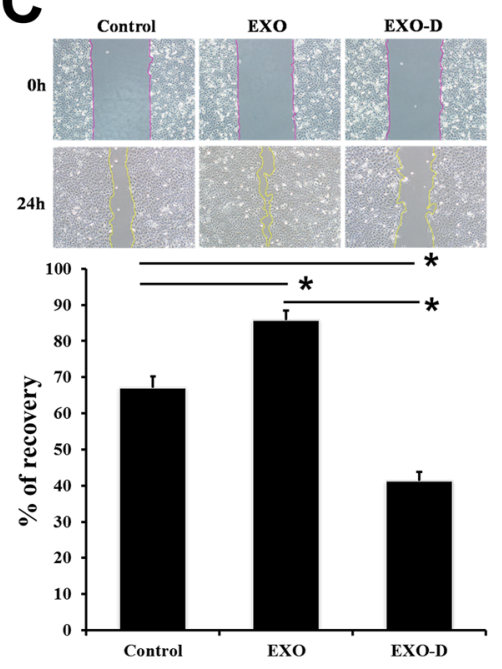

D
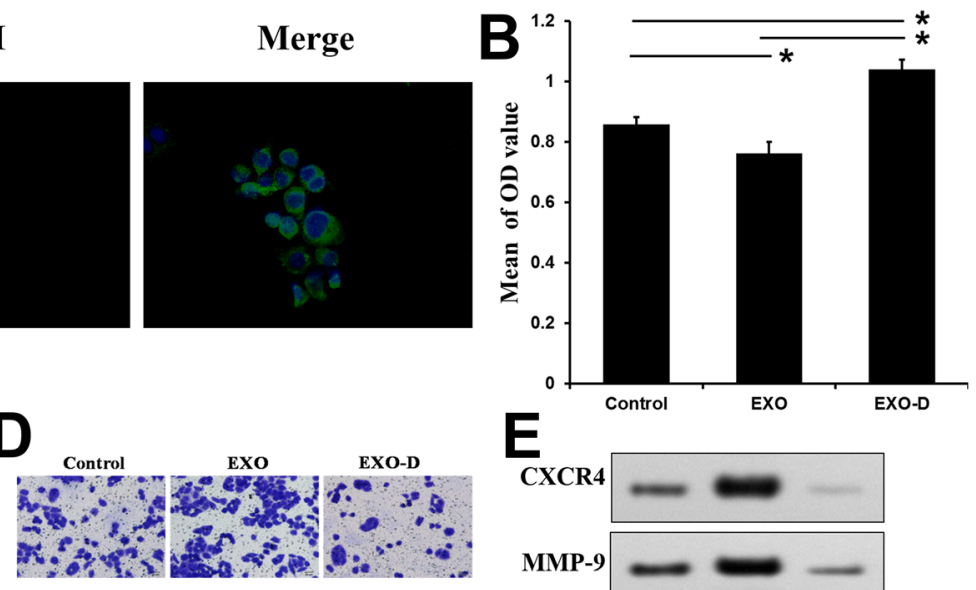

E

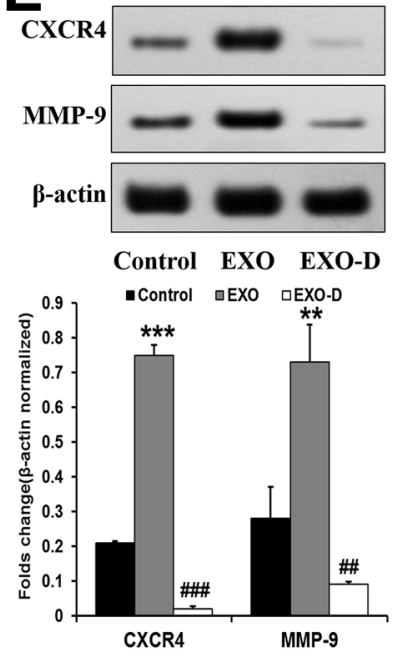

Figure 2: Panc02-H7-derived exosomes promote metastatis-related characteristics in vitro. Panc02 cells tookup PKH67labeled Panc02-H7EXOs. Numerous green fluorescently-labeled exosomes were observed inside cells after 5 h (400× magnification). (A) The MTT cell adhesion assay indicated that Panc02-H7 EXOs decrease Panc02 cell adhesion, (B) Wound-healing assays indicated that Panc02-H7 EXOs enhanced Panc02 cell migration (200×magnification). (C) Transwell chamber invasion assays showed that Panc02-H7 EXOs increased Panc02 cell invasion (200×magnification). (D) Western blotting indicated that Panc02-H7 EXOs increased Panc02 cell migration and invasion via CXCR4 and MMP-9 signaling. (E) $\mathrm{n}=3$ /group. ${ }^{*} \mathrm{P}<0.05,{ }^{*} \mathrm{P}<0.01,{ }^{*} * * \mathrm{P}<0.001$ compared to control; \#P $<0.05$, $\# \# \mathrm{P}<0.01, \# \# \# \mathrm{P}<0.001$ compared to $\mathrm{EXO}-\mathrm{D}$. 

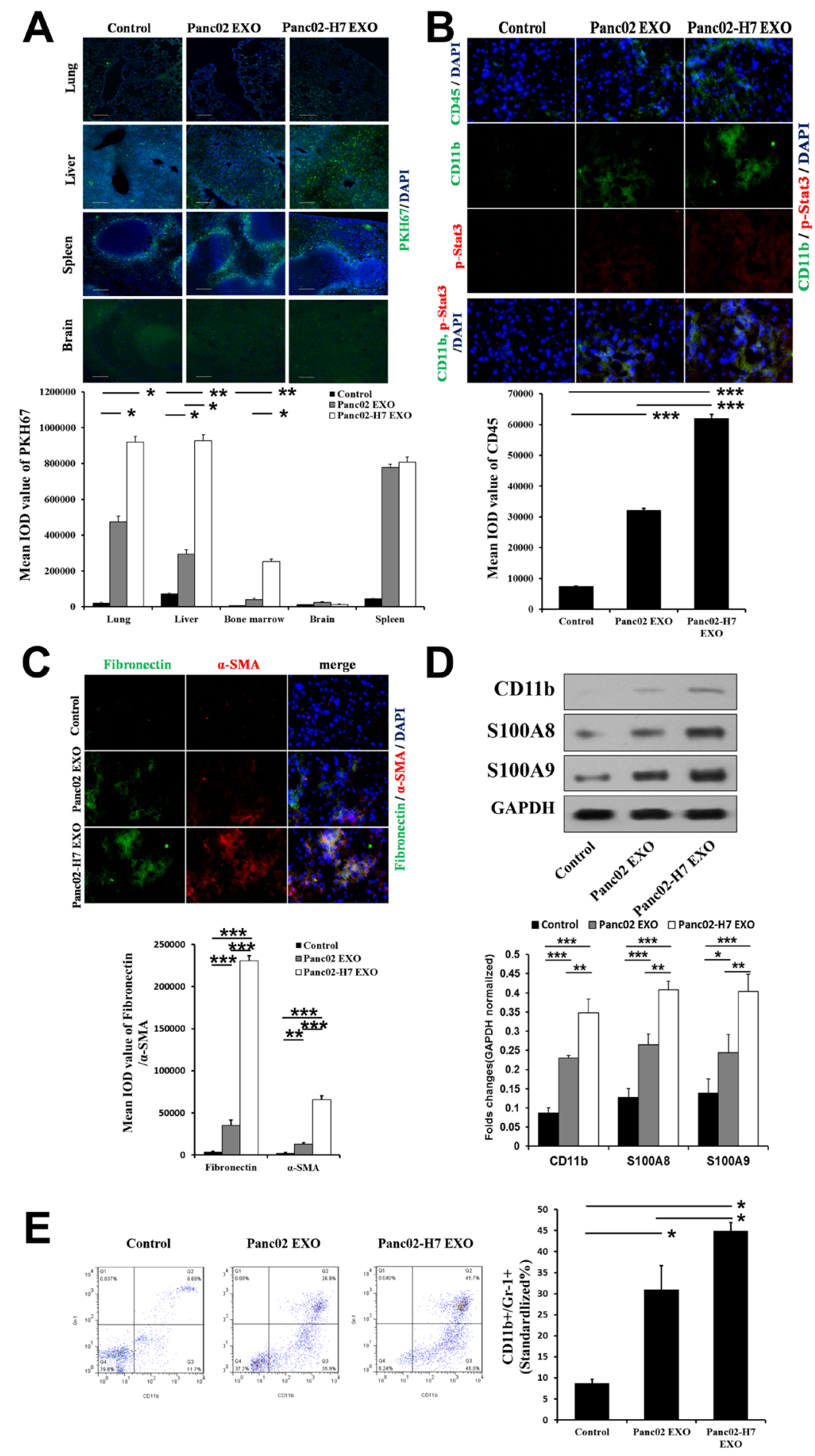

Figure 3: Pancreatic cancer-derived exosomes mediate liver pre-metastatic niche formation. Confocal microscopy (lung, liver, spleen, brain) of PKH67-labeled Panc02 EXO and Panc02-H7 EXO tissue distribution (green) 24 hpi. (A) PKH-67-labeled liposomes served as controls (scale bar $=100 \mu \mathrm{m}$ ). Histogram shows exosome tissue distribution quantification ( $\mathrm{n}=5 /$ group). CD45, $\mathrm{p}$-Stat3, and CD11b IF staining in liver sections from controls (left) and mice treated with Panc02 EXOs(middle) or Panc02-H7 EXOs (right) for 12 $\mathrm{d}$ without tumor challenge. (B) Histogram shows infiltrating CD45 cell quantification. FN and $\alpha$-SMA IF staining in liver sections from controls (top) and mice treated with Panc02 EXOs(middle) or Panc02-H7 EXOs (bottom) for $12 \mathrm{~d}$ without tumor challenge. (C) Histogram shows infiltrating $\alpha$-SMA ${ }^{+} \mathrm{hStCs}$ and FN expression quantification(400× magnification; $\mathrm{n}=5 /$ group). Western blotting analysis showed upregulated S100A8 and S100A9 in livers treated with Panc02-H7-derived exosomes. Histogram shows expression of the three proteins in three groupsas determined by densitometric analysis ( $\mathrm{n}=3 /$ group). (D) Pancreatic cancer-derived exosomes induce MDSC accumulation in peripheral blood. (E) Representative flow cytometric plots (left) and quantification (right) of $\mathrm{CD} 11 \mathrm{~b}+\mathrm{GR} 1^{+} \mathrm{MDSCs}$ ( $\mathrm{n}=5 /$ group). ${ }^{\mathrm{P}} \mathrm{P}<0.05$, $* * \mathrm{P}<0.01, * * * \mathrm{P}<0.001$. 
8). GAPDH was used as loading control. Protein band densities analyzed quantitatively using ImageJ verified that expression patterns were consistent with iTRAQ quantitative proteomics results.

\section{DISCUSSION}

There is currently no standardized exosome isolation technique. In this study, we isolated exosomes by collecting cell-conditioned medium from ordinary culture flasks. We purified exosomes using ultracentrifugation combined with sucrose density gradient centrifugation. However, this method was time-consuming, labor intensive and resulted in low yield. Jeppesen, et al. developed an exosome collection strategy using CLAD1000 bioreactors and a 10-kDa semi-permeable membrane. Their method increases exosome yields 13-16fold compared to isolation from flasks [13].
Exosomes as cell-free messengers play important roles in cell-cell communication, and are likely mediators of the metastatic cascade $[5,14-16]$. This study examined the role of exosomes in cancer adhesion, migration, and invasion. Chemokines and their receptors contribute to cancer metastasis, particularly stromal cell-derived factor- $1 \alpha$ and its receptor, CXCR4 [17-18]. MMP-9 is a downstream signaling molecule of CXCR4 and is critical for cancer cell migration and invasion [19]. We found that Panc02-H7 EXO treatment increased Panc02 cell migration and invasion, and upregulated CXCR4 and MMP-9 compared with controls, indicating that CXCR4 and MMP-9 signaling may enhance Panc02 cell metastatic capabilities.

Fluorescent labeling allowed for direct exosome visualization in our study. Consistent with other groups, we found that exosome tissue distribution mimicked the organotropic distribution of the cell line of origin [20].

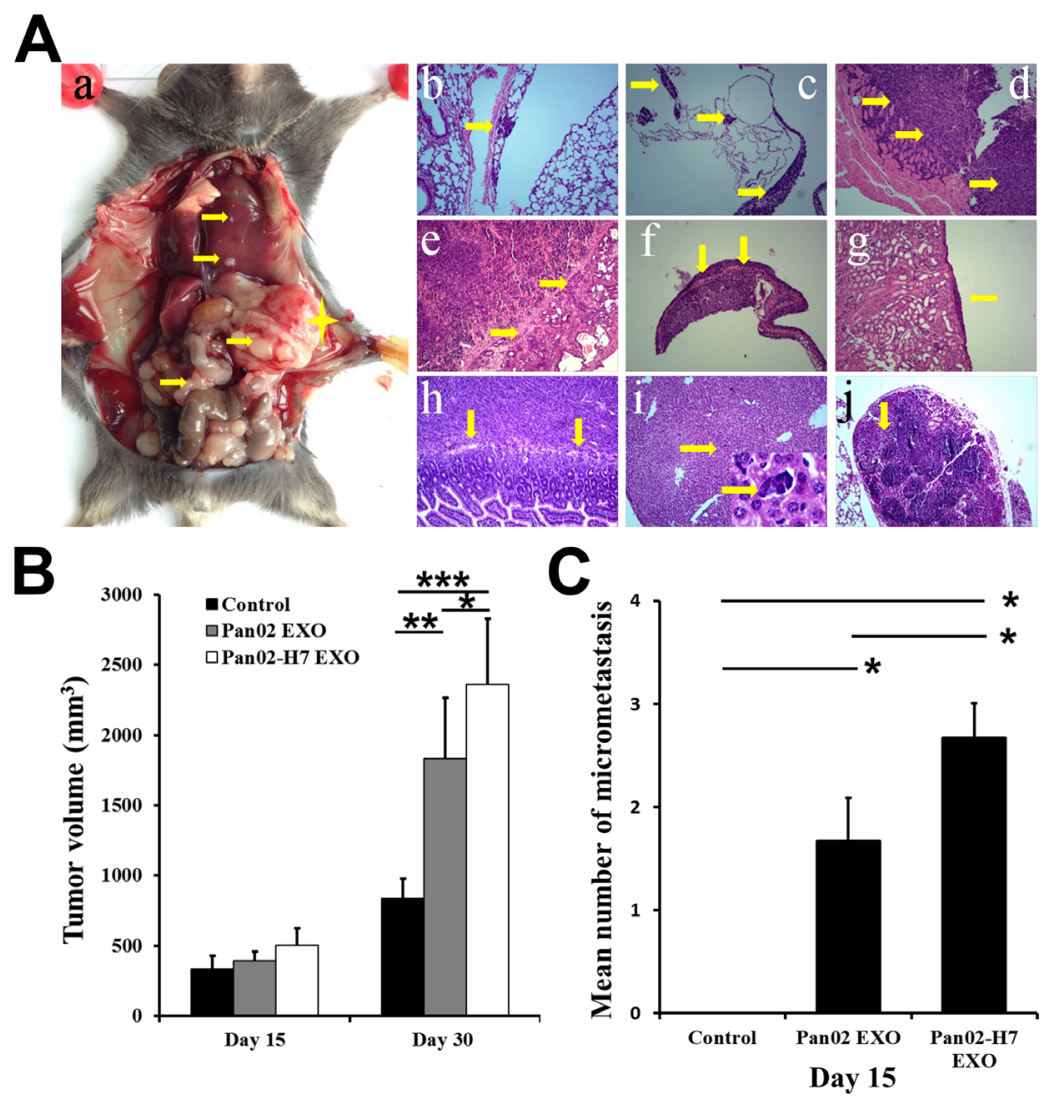

Figure 4: Pancreatic cancer-derived exosomes promote tumor growth and metastasis. Representative macro-anatomy and H\&E-stained images of Panc02-H7 EXO-treated mice 30 d post-SOI. (A) A blue star marks primary tumor locations; arrows indicate metastatic sites in the peritoneal cavity. (Aa) Arrows showing lung micrometastasis (Ab), pleura metastasis (Ac), tumor invasion of the diaphragm (Ad), metastasis to spleen (Ae), tumor invasion of the adrenal gland (Af), metastasis to the kidney (Ag), tumor invasion of the small intestine (Ah), micrometastasis of the liver(lower right shows enlarged image) (Ai), and metastasis to lymph nodes (Aj) (magnification, 100×). Primary tumor volume in mice treated with PBS, Panc02 EXOs, orPanc02-H7 EXOs at 15 and $30 \mathrm{~d}$ post-SOI. (B) Number of micrometastases in mice treated with PBS, Panc02 EXOs, or Panc02-H7 EXOsat 15d post-SOI (n=6/group). (C) *P $<0.05$, $* * \mathrm{P}<0.01, * * * \mathrm{P}<0.001$ 
The organotropic nature of exosomes is largely attributed to a specific exosomal surface integrin repertoire that dictates exosome homing to distant organs and uptake by target cells. Our exosome proteomic analysis identified multiple integrin subunits (beta-1, alpha-3, beta-3, beta4, alpha 5, alpha-V, alpha-6, and alpha-X) (Table 3) that could be associated with pancreatic cancer metastasis to multiple organs. Our model allowed us to study the effects of exosome accumulation in pre-metastatic organs and to determine whether or not such accumulation could prime the liver microenvironment for metastatic tumor cell colonization.

The liver is the main site of metastatic disease from gastrointestinal malignancies, such as pancreatic, colon, and gastric carcinomas. The term "liver premetastatic niche" was coined to describe a liver microenvironment permissive to metastatic outgrowth in advance of cancer cell arrival, established through soluble-factor activity and exosome release by the primary tumor. The liver metastatic microenvironment is composed of resident Kupffer cells (KCs), hStCs, bone marrow-derived cells (BMDCs), extracellular matrix components, and secreted soluble factors, such as cytokines and chemokines. Costa-Silva, et al. showed that PDAC-derived exosomes containing macrophage migration inhibitory factor (MIF) are selectively taken up by hepatic KCs, upregulating TGF- $\beta$ [8]. This increases fibronectin production by $\mathrm{hStCs}$ and promotes liver recruitment of bone marrow-derived neutrophils and macrophages, completing pre-metastatic niche formation.Nielsen, et al. showed that metastasisassociated macrophages (MAMs) activate resident hStC transformation into myofibroblasts, resulting in a fibrotic microenvironment that sustains metastatic tumor growth [21]. Macrophages in the liver include embryonically derived tissue-resident macrophages (KCs) and infiltrating macrophages derived from inflammatory monocytes (IMs) that originate from the bone marrow (BM) [22]. These macrophages can also trigger hStC activation and fibrogenesis [23], a process important in the early stages of extra-vascular tumor expansion. Both of these studies emphasized that macrophages play
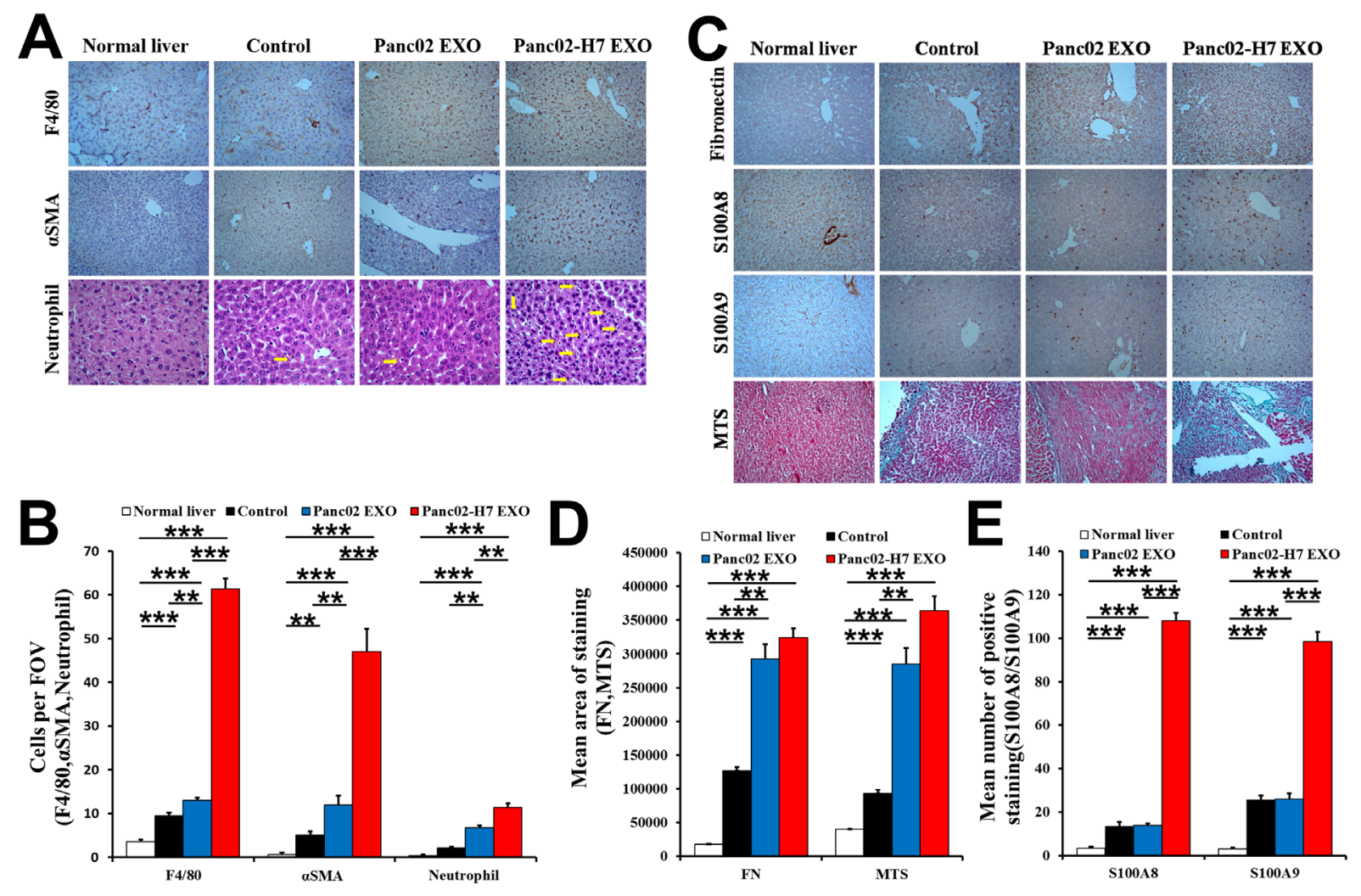

Figure 5: Pancreatic cancer-derived exosomes induce inflammation and fibrotic microenvironment formation in the liver. IHC analysis and histopathological examination of macrophages (F4/80), hStCs ( $\alpha$-SMA), and neutrophils in liver metastatic niches of naïve mice and mice treated with PBS, Panc02 EXOs, or Panc02-H7 EXOs at 30d post-SOI (arrow shows neutrophils in liver). (A) Representative histogram shows quantification of $\mathrm{F} 4 / 80^{+}$macrophages, $\alpha-\mathrm{SMA}^{+} \mathrm{hStCs}$, and neutrophils. (B) Identification of FN, S100A8, and S100A9 as inflammatory mediators, and collagen deposition in the liver metastatic niche. (C) Representative histogram shows FN and MTS quantification. (D) Representative histogram shows S100A8 and S100A9 quantification. (E) $\mathrm{n}=6$ /group. ${ }^{* *} \mathrm{P}<0.01,{ }^{* * *} \mathrm{P}<0.001 .10$ fields assessed per sample. FOV, field of view. 
key roles in PDAC liver metastasis. Our IHC analysis results also showed that $\mathrm{F} 4 / 80^{+}$macrophages were increased in Panc02-H7 EXO-treated livers compared with controls and normal liver. However, F4/80, a cell surface marker used to identify KCs, is also expressed on recruited monocytes, and strategies used to eliminate macrophages in vivo are not KC specific. Thus, our results require further verification.

Under physiological conditions, quiescent $\mathrm{hStCs}$ in the space of Disse [24] become activated myofibroblasts that express $\alpha$-SMA and produce ECM rich in collagens I and IV in response to liver damage, inflammatory stimuli, and tumor cells [25-26]. Chemokines and cytokines released by $\alpha-\mathrm{SMA}^{+} \mathrm{hStCs}$ also recruit inflammatory/immune cells and enhance premetastatic niche formation. We observed increased $\alpha-\mathrm{SMA}^{+} \mathrm{hStC}$ frequencies in Panc02-H7 EXO-treated livers, suggesting that activated $\alpha-\mathrm{SMA}^{+} \mathrm{hStCs}$ produced most of the FN in both the pre-metastatic and metastatic niches.Masson's trichrome staining also showed higher degrees of fibrosis in livers treated with either Panc02or Panc02-H7-derived exosomes. We also found that Panc02-H7 EXO treatment increased neutrophil number and upregulated S100A8 and S100A9 in the mouse liver. Neutrophils may be mobilized into liver premetastatic niches by S100A8 and S100A9 or chemokines and cytokines secreted by activated macrophages, endothelial cells, or cancer cells.
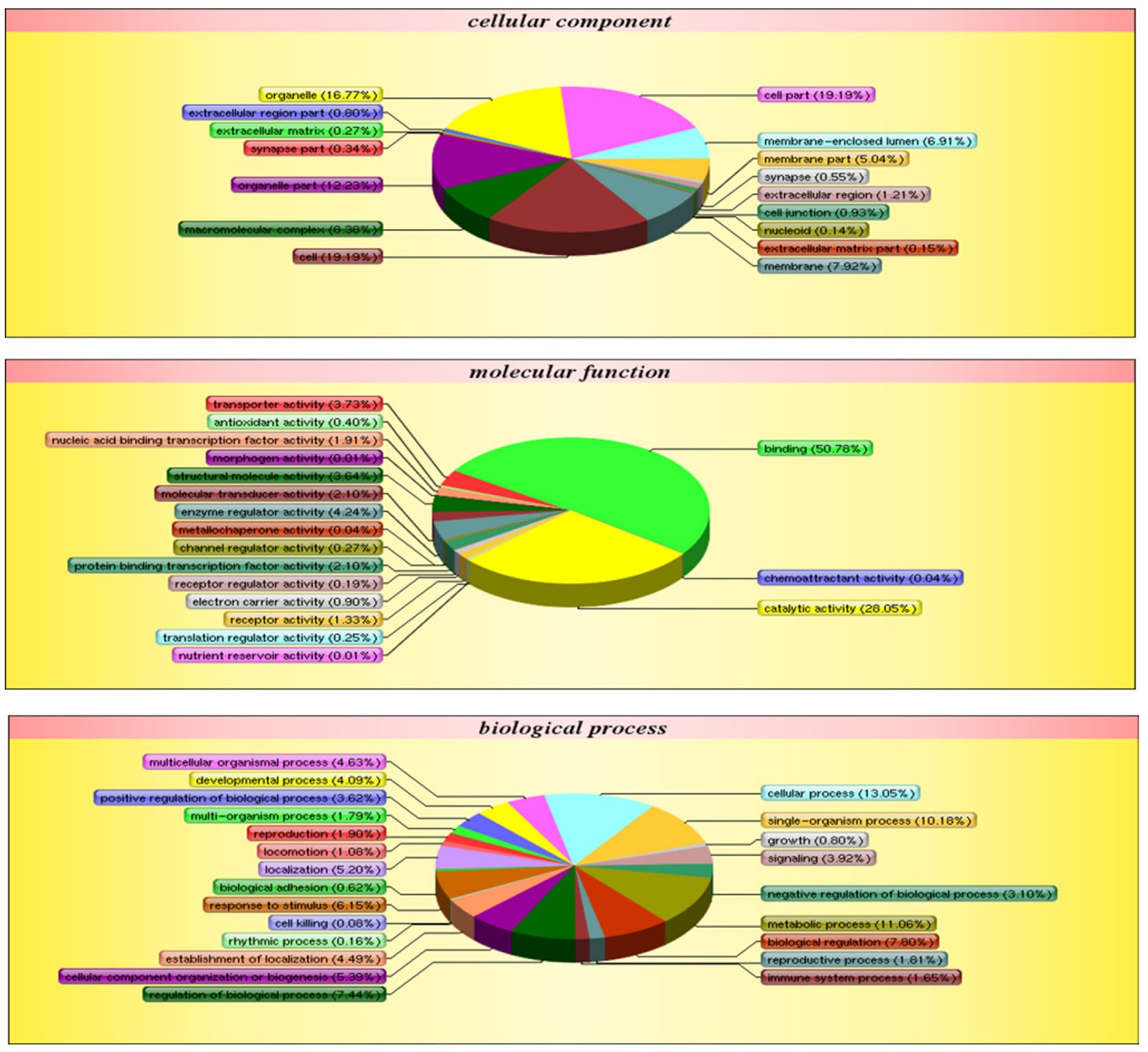

Figure 6: Panc02 EXO and Panc02-H7 EXO proteins identified via iTRAQ quantitative proteomic analysis. GO enrichment analysis of 4,517exosomal proteins via Blast2go. Proteins were classified by cellular component (CC), molecular function (MF), or biological process (BP). 
Table 1: 79 proteins were differentially-expressed between Panc02 EXOs and Panc02-H7 EXOs

\begin{tabular}{|c|c|c|c|c|c|c|}
\hline Hits & Accession & Protein name & Expression & $114 / 116$ & $119 / 118$ & Mean \\
\hline 1 & $\begin{array}{l}\text { sp|O88477|IF2B1_ } \\
\text { MOUSE }\end{array}$ & $\begin{array}{l}\text { Insulin-like growth } \\
\text { factor } 2 \text { mRNA- } \\
\text { binding protein } 1\end{array}$ & up & 1.937 & 2.205 & 2.071 \\
\hline 2 & $\begin{array}{l}\operatorname{tr} \mid \text { G3XA48|G3XA48_ } \\
\text { MOUSE }\end{array}$ & $\begin{array}{l}\text { Isopentenyl- } \\
\text { diphosphate Delta- } \\
\text { isomerase } 1\end{array}$ & up & 1.548 & 1.272 & 1.41 \\
\hline 3 & $\begin{array}{l}\text { sp|P70460|VASP } \\
\text { MOUSE }\end{array}$ & $\begin{array}{l}\text { Vasodilator-stimulated } \\
\text { phosphoprotein }\end{array}$ & up & 1.429 & 1.514 & 1.472 \\
\hline 4 & $\begin{array}{l}\text { sp|P47930|FOSL2_ } \\
\text { MOUSE }\end{array}$ & Fos-related antigen 2 & up & 1.596 & 1.687 & 1.642 \\
\hline 5 & $\begin{array}{l}\operatorname{tr|Q3TT92|Q3TT92~} \\
\text { MOUSE }\end{array}$ & $\begin{array}{l}\text { Dihydropyrimidinase- } \\
\text { related protein } 3\end{array}$ & up & 3.193 & 3.973 & 3.583 \\
\hline 6 & $\begin{array}{l}\text { sp|Q8K2Q9|SHOT1_ } \\
\text { MOUSE }\end{array}$ & Shootin-1 & up & 1.485 & 1.548 & 1.517 \\
\hline 7 & $\begin{array}{l}\operatorname{tr}|\mathrm{Q} 3 \mathrm{U} 125| \mathrm{Q} 3 \mathrm{U} 125_{-} \\
\text {MOUSE }\end{array}$ & $\begin{array}{l}\text { Redox-regulatory } \\
\text { protein FAM213A }\end{array}$ & up & 2.076 & 1.796 & 1.936 \\
\hline 8 & $\begin{array}{l}\operatorname{tr}|\mathrm{Q} 3 \mathrm{TXR} 4| \mathrm{Q} 3 \mathrm{TXR} 4 \\
\text { MOUSE }\end{array}$ & $\begin{array}{l}\text { Transcription factor } \\
\text { jun-B }\end{array}$ & up & 1.442 & 1.639 & 1.541 \\
\hline 9 & $\begin{array}{l}\text { sp|P50543|S10AB } \\
\text { MOUSE }\end{array}$ & Protein S100-A11 & up & 2.692 & 1.942 & 2.317 \\
\hline 10 & $\begin{array}{l}\operatorname{tr}|\mathrm{Q} 3 T S Q 1| \mathrm{Q} 3 T S Q 1 \\
\text { MOUSE }\end{array}$ & $\begin{array}{l}\text { Sodium/potassium- } \\
\text { transporting ATPase } \\
\text { subunit beta }\end{array}$ & up & 1.917 & 1.813 & 1.865 \\
\hline 11 & $\begin{array}{l}\text { sp|Q8BV49|IFIX_ } \\
\text { MOUSE }\end{array}$ & $\begin{array}{l}\text { Pyrin and HIN } \\
\text { domain-containing } \\
\text { protein } 1\end{array}$ & up & 1.548 & 1.573 & 1.561 \\
\hline 12 & $\begin{array}{l}\text { sp|P18406|CYR61_ } \\
\text { MOUSE }\end{array}$ & Protein CYR61 & up & 1.359 & 1.529 & 1.444 \\
\hline 13 & $\begin{array}{l}\text { sp|Q9CQ69|QCR8_ } \\
\text { MOUSE }\end{array}$ & $\begin{array}{l}\text { Cytochrome b-c1 } \\
\text { complex subunit } 8\end{array}$ & up & 1.353 & 1.983 & 1.668 \\
\hline 14 & $\begin{array}{l}\text { sp|P05784|K1C18 } \\
\text { MOUSE }\end{array}$ & $\begin{array}{l}\text { Keratin, type I } \\
\text { cytoskeletal } 18\end{array}$ & up & 1.555 & 1.536 & 1.546 \\
\hline 15 & $\begin{array}{l}\text { sp|Q9CR98|F136A_ } \\
\text { MOUSE }\end{array}$ & Protein FAM136A & up & 1.539 & 1.254 & 1.397 \\
\hline 16 & $\begin{array}{l}\operatorname{tr} \mid \text { E0CXM9|E0CXM9 } \\
\text { MOUSE }\end{array}$ & $\begin{array}{l}\text { Zinc finger protein- } \\
\text { like } 1\end{array}$ & up & 1.68 & 1.05 & 1.365 \\
\hline 17 & $\begin{array}{l}\text { sp|Q9R1Q7|PLP2 } \\
\text { MOUSE }\end{array}$ & Proteolipid protein 2 & up & 2.792 & 1.279 & 2.036 \\
\hline 18 & $\begin{array}{l}\text { sp|Q91XV3|BASP1_ } \\
\text { MOUSE }\end{array}$ & $\begin{array}{l}\text { Brain acid soluble } \\
\text { protein } 1\end{array}$ & up & 2.963 & 3.513 & 3.238 \\
\hline 19 & $\begin{array}{l}\text { sp|Q9DCV7|K2C7 } \\
\text { MOUSE }\end{array}$ & $\begin{array}{l}\text { Keratin, type II } \\
\text { cytoskeletal } 7\end{array}$ & up & 4.188 & 4.47 & 4.329 \\
\hline
\end{tabular}

(Continued) 


\begin{tabular}{|c|c|c|c|c|c|c|}
\hline Hits & Accession & Protein name & Expression & $114 / 116$ & $119 / 118$ & Mean \\
\hline 20 & $\begin{array}{l}\operatorname{tr} \mid \text { F6ZFU0|F6ZFU0 } \\
\text { MOUSE }\end{array}$ & $\begin{array}{l}\text { Elongation factor } \\
\text { 1-delta }\end{array}$ & up & 1.016 & 1.578 & 1.297 \\
\hline 21 & $\begin{array}{l}\text { sp|Q8R5J9|PRAF3 } \\
\text { MOUSE }\end{array}$ & $\begin{array}{l}\text { PRA1 family protein } \\
3\end{array}$ & up & 1.32 & 1.599 & 1.46 \\
\hline 22 & $\begin{array}{l}\operatorname{tr|D3YUW7|D3YUW7} \\
\text { MOUSE }\end{array}$ & Cingulin & up & 2.034 & 2.236 & 2.135 \\
\hline 23 & $\begin{array}{l}\operatorname{tr}|\mathrm{Q} 3 \mathrm{U} 7 \mathrm{D} 2| \mathrm{Q} 3 \mathrm{U} 7 \mathrm{D} 2 \\
\text { MOUSE }\end{array}$ & $\begin{array}{l}\text { Ribosomal protein } \\
\text { L15 }\end{array}$ & up & 1.52 & 1.049 & 1.285 \\
\hline 24 & $\begin{array}{l}\text { tr|Q3TGQ3|Q3TGQ3_- } \\
\text { MOUSE }\end{array}$ & $\begin{array}{l}\text { Putative } \\
\text { uncharacterized } \\
\text { protein }\end{array}$ & up & 1.401 & 1.53 & 1.466 \\
\hline 25 & $\begin{array}{l}\operatorname{tr} \mid \text { Q3TLJ9|Q3TLJ9 } \\
\text { MOUSE }\end{array}$ & $\begin{array}{l}\text { Putative } \\
\text { uncharacterized } \\
\text { protein }\end{array}$ & up & 1.553 & 1.357 & 1.455 \\
\hline 26 & $\begin{array}{l}\text { sp|P62077|TIM8B } \\
\text { MOUSE }\end{array}$ & $\begin{array}{l}\text { Mitochondrial import } \\
\text { inner membrane } \\
\text { translocase subunit } \\
\text { Tim8 }\end{array}$ & up & 1.51 & 1.359 & 1.435 \\
\hline 27 & $\begin{array}{l}\operatorname{tr}|\mathrm{G} 5 \mathrm{E} 850| \mathrm{G} 5 \mathrm{E} 850 \\
\text { MOUSE }\end{array}$ & $\begin{array}{l}\text { Cytochrome b-5, } \\
\text { isoform CRA_a }\end{array}$ & up & 1.323 & 1.538 & 1.431 \\
\hline 28 & $\begin{array}{l}\text { sp|Q8BGZ7|K2C75 } \\
\text { MOUSE }\end{array}$ & $\begin{array}{l}\text { Keratin, type II } \\
\text { cytoskeletal } 75\end{array}$ & up & 1.203 & 1.771 & 1.487 \\
\hline 29 & $\begin{array}{l}\operatorname{tr}|\mathrm{D} 3 Z 125| \mathrm{D} 3 Z 125 \\
\text { MOUSE }\end{array}$ & Tumor protein D52 & up & 1.596 & 1.385 & 1.491 \\
\hline 30 & $\begin{array}{l}\text { sp|P45377|ALD2 } \\
\text { MOUSE }\end{array}$ & $\begin{array}{l}\text { Aldose reductase- } \\
\text { related protein } 2\end{array}$ & up & 1.759 & 1.442 & 1.601 \\
\hline 31 & $\begin{array}{l}\operatorname{tr}|\mathrm{B} 2 \mathrm{RUC1}| \mathrm{B} 2 \mathrm{RUC1} \\
\text { MOUSE }\end{array}$ & Tpd5211 protein & up & 1.425 & 1.699 & 1.562 \\
\hline 32 & $\begin{array}{l}\text { sp|P19001|K1C19_ } \\
\text { MOUSE }\end{array}$ & $\begin{array}{l}\text { Keratin, type I } \\
\text { cytoskeletal } 19\end{array}$ & up & 1.727 & 1.819 & 1.773 \\
\hline 33 & $\begin{array}{l}\operatorname{tr}|\mathrm{A} 2 \mathrm{~A} 547| \mathrm{A} 2 \mathrm{~A} 547 \\
\text { MOUSE }\end{array}$ & $\begin{array}{l}\text { Ribosomal protein } \\
\text { L19 }\end{array}$ & up & 1.166 & 1.502 & 1.334 \\
\hline 1 & $\begin{array}{l}\operatorname{tr} \mid \text { Q9D089|Q9D089_ } \\
\text { MOUSE }\end{array}$ & $\begin{array}{l}\text { Putative } \\
\text { uncharacterized } \\
\text { protein }\end{array}$ & down & 0.929 & 0.597 & 0.763 \\
\hline 2 & $\begin{array}{l}\operatorname{tr|J3QN31|J3QN31} \\
\text { MOUSE }\end{array}$ & $\begin{array}{l}\text { Adenylosuccinate } \\
\text { synthetase isozyme } 1\end{array}$ & down & 0.499 & 0.504 & 0.502 \\
\hline 3 & $\begin{array}{l}\operatorname{tr}|\mathrm{F} 8 \mathrm{VQJ} 3| \mathrm{F} 8 \mathrm{VQJ} 3 \\
\text { MOUSE }\end{array}$ & $\begin{array}{l}\text { Laminin subunit } \\
\text { gamma-1 }\end{array}$ & down & 0.57 & 0.644 & 0.607 \\
\hline 4 & $\begin{array}{l}\text { sp|Q3UHD3|MTUS2_ } \\
\text { MOUSE }\end{array}$ & $\begin{array}{l}\text { Microtubule- } \\
\text { associated tumor } \\
\text { suppressor candidate } \\
2 \text { homolog }\end{array}$ & down & 0.852 & 0.646 & 0.749 \\
\hline
\end{tabular}

(Continued) 


\begin{tabular}{|c|c|c|c|c|c|c|}
\hline Hits & Accession & Protein name & Expression & $114 / 116$ & $119 / 118$ & Mean \\
\hline 5 & $\begin{array}{l}\text { sp|Q61599|GDIR2 } \\
\text { MOUSE }\end{array}$ & $\begin{array}{l}\text { Rho GDP-dissociation } \\
\text { inhibitor } 2\end{array}$ & down & 0.731 & 0.588 & 0.66 \\
\hline 6 & $\begin{array}{l}\operatorname{tr}|\mathrm{Q} 3 T D U 5| \mathrm{Q} 3 T D U 5 \\
\text { MOUSE }\end{array}$ & $\begin{array}{l}\text { Milk fat globule- } \\
\text { EGF factor } 8 \text { protein, } \\
\text { isoform CRA_a }\end{array}$ & down & 0.688 & 0.645 & 0.667 \\
\hline 7 & $\begin{array}{l}\text { sp|P16125|LDHB_ } \\
\text { MOUSE }\end{array}$ & $\begin{array}{l}\text { L-lactate } \\
\text { dehydrogenase B } \\
\text { chain }\end{array}$ & down & 0.179 & 0.165 & 0.172 \\
\hline 8 & $\begin{array}{l}\text { sp|Q8R3P0|ACY2 } \\
\text { MOUSE }\end{array}$ & Aspartoacylase & down & 0.549 & 0.619 & 0.584 \\
\hline 9 & $\begin{array}{l}\text { sp|Q6ZPE2|MTMR5 } \\
\text { MOUSE }\end{array}$ & $\begin{array}{l}\text { Myotubularin-related } \\
\text { protein } 5\end{array}$ & down & 0.634 & 0.875 & 0.755 \\
\hline 10 & $\begin{array}{l}\text { sp|Q8BFU3|RN214_ } \\
\text { MOUSE }\end{array}$ & $\begin{array}{l}\text { RING finger protein } \\
214\end{array}$ & down & 0.652 & 0.866 & 0.759 \\
\hline 11 & $\begin{array}{l}\text { sp|Q61553|FSCN1_ } \\
\text { MOUSE }\end{array}$ & Fascin & down & 0.273 & 0.282 & 0.278 \\
\hline 12 & $\begin{array}{l}\text { sp|P21981|TGM2_ } \\
\text { MOUSE }\end{array}$ & $\begin{array}{l}\text { Protein-glutamine } \\
\text { gamma- } \\
\text { glutamyltransferase } 2\end{array}$ & down & 0.711 & 0.605 & 0.658 \\
\hline 13 & $\begin{array}{l}\text { sp|P17563|SBP1 } \\
\text { MOUSE }\end{array}$ & $\begin{array}{l}\text { Selenium-binding } \\
\text { protein } 1\end{array}$ & down & 0.488 & 0.528 & 0.508 \\
\hline 14 & $\begin{array}{l}\text { sp|Q810Q5|NMES1_ } \\
\text { MOUSE }\end{array}$ & $\begin{array}{l}\text { Normal mucosa of } \\
\text { esophagus-specific } \\
\text { gene } 1 \text { protein }\end{array}$ & down & 0.807 & 0.515 & 0.661 \\
\hline 15 & $\begin{array}{l}\operatorname{tr|} \text { E9PVM7|E9PVM7_ } \\
\text { MOUSE }\end{array}$ & $\begin{array}{l}\text { Glutathione } \\
\text { S-transferase Mu } 5\end{array}$ & down & 0.803 & 0.644 & 0.724 \\
\hline 16 & $\begin{array}{l}\text { sp|Q8BVA5|CB043 } \\
\text { MOUSE }\end{array}$ & $\begin{array}{l}\text { UPF0554 protein } \\
\text { C2orf43 homolog }\end{array}$ & down & 0.536 & 0.358 & 0.447 \\
\hline 17 & $\begin{array}{l}\operatorname{tr} \mid \text { A2AE89|A2AE89 } \\
\text { MOUSE }\end{array}$ & $\begin{array}{l}\text { Glutathione } \\
\text { S-transferase Mu } 1\end{array}$ & down & 0.473 & 0.652 & 0.563 \\
\hline 18 & $\begin{array}{l}\text { sp|P48428|TBCA_ } \\
\text { MOUSE }\end{array}$ & $\begin{array}{l}\text { Tubulin-specific } \\
\text { chaperone A }\end{array}$ & down & 0.661 & 0.76 & 0.711 \\
\hline 19 & $\begin{array}{l}\text { sp|Q4VAA2|CDV3 } \\
\text { MOUSE }\end{array}$ & Protein CDV3 & down & 0.556 & 0.91 & 0.733 \\
\hline 20 & $\begin{array}{l}\text { sp|P06801|MAOX } \\
\text { MOUSE }\end{array}$ & $\begin{array}{l}\text { NADP-dependent } \\
\text { malic enzyme }\end{array}$ & down & 0.712 & 0.661 & 0.687 \\
\hline 21 & $\begin{array}{l}\text { sp|P60824|CIRBP } \\
\text { MOUSE }\end{array}$ & $\begin{array}{l}\text { Cold-inducible RNA- } \\
\text { binding protein }\end{array}$ & down & 0.671 & 0.62 & 0.646 \\
\hline 22 & $\begin{array}{l}\operatorname{tr}|\mathrm{Q} 3 \mathrm{UGY} 5| \mathrm{Q} 3 \mathrm{UGY} 5 \\
\text { MOUSE }\end{array}$ & $\begin{array}{l}\text { Putative } \\
\text { uncharacterized } \\
\text { protein }\end{array}$ & down & 0.441 & 0.523 & 0.482 \\
\hline 23 & $\begin{array}{l}\text { sp|Q8BMK4|CKAP4_ } \\
\text { MOUSE }\end{array}$ & $\begin{array}{l}\text { Cytoskeleton- } \\
\text { associated protein } 4\end{array}$ & down & 0.336 & 0.529 & 0.433 \\
\hline
\end{tabular}

(Continued) 


\begin{tabular}{|c|c|c|c|c|c|c|}
\hline Hits & Accession & Protein name & Expression & $114 / 116$ & $119 / 118$ & Mean \\
\hline 24 & $\begin{array}{l}\text { sp|P05063|ALDOC_ } \\
\text { MOUSE }\end{array}$ & $\begin{array}{l}\text { Fructose-bisphosphate } \\
\text { aldolase C }\end{array}$ & down & 0.651 & 0.558 & 0.605 \\
\hline 25 & $\begin{array}{l}\operatorname{tr}|\mathrm{E} 0 \mathrm{CY} 47| \mathrm{E} 0 \mathrm{CY} 47 \\
\text { MOUSE }\end{array}$ & $\begin{array}{l}\text { 1-phosphatidylinositol } \\
4,5 \text {-bisphosphate } \\
\text { phosphodiesterase } \\
\text { eta-1 }\end{array}$ & down & 0.649 & 0.628 & 0.639 \\
\hline 26 & $\begin{array}{l}\operatorname{tr}|\mathrm{Q} 3 \mathrm{TNC} 8| \mathrm{Q} 3 \mathrm{TNC} 8 \\
\text { MOUSE }\end{array}$ & $\begin{array}{l}\text { Putative } \\
\text { uncharacterized } \\
\text { protein }\end{array}$ & down & 0.632 & 0.522 & 0.577 \\
\hline 27 & $\begin{array}{l}\text { sp|Q60928|GGT1_ } \\
\text { MOUSE }\end{array}$ & $\begin{array}{l}\text { Gamma- } \\
\text { glutamyltranspeptidase } \\
1\end{array}$ & down & 0.589 & 0.592 & 0.591 \\
\hline 28 & $\begin{array}{l}\text { sp|P14873|MAP1B_ } \\
\text { MOUSE }\end{array}$ & $\begin{array}{l}\text { Microtubule- } \\
\text { associated protein }\end{array}$ & down & 0.62 & 0.618 & 0.619 \\
\hline 29 & $\begin{array}{l}\operatorname{tr}|\mathrm{Q} 5 \mathrm{~F} 2 \mathrm{~B} 1| \mathrm{Q} 5 \mathrm{~F} 2 \mathrm{~B} 1 \_ \\
\text {MOUSE }\end{array}$ & $\begin{array}{l}\text { Mannose-P-dolichol } \\
\text { utilization defect } 1 \\
\text { protein }\end{array}$ & down & 0.797 & 0.661 & 0.729 \\
\hline 30 & $\begin{array}{l}\operatorname{tr}|\mathrm{Q} 3 \mathrm{TJK} 3| \mathrm{Q} 3 \mathrm{TJK} 3 \\
\text { MOUSE }\end{array}$ & $\begin{array}{l}\text { Putative } \\
\text { uncharacterized } \\
\text { protein }\end{array}$ & down & 0.551 & 0.468 & 0.51 \\
\hline 31 & $\begin{array}{l}\operatorname{tr}|\mathrm{Q} 3 \mathrm{TDX} 7| \mathrm{Q} 3 \mathrm{TDX} 7_{-} \\
\text {MOUSE }\end{array}$ & $\begin{array}{l}\text { Extracellular matrix } \\
\text { protein } 1\end{array}$ & down & 0.451 & 0.388 & 0.42 \\
\hline 32 & $\begin{array}{l}\operatorname{tr}|\mathrm{Q} 8 \mathrm{CEU} 1| \mathrm{Q} 8 \mathrm{CEU} 1 \\
\text { MOUSE }\end{array}$ & $\begin{array}{l}\text { Putative } \\
\text { uncharacterized } \\
\text { protein }\end{array}$ & down & 0.644 & 0.74 & 0.692 \\
\hline 33 & $\begin{array}{l}\text { sp|P02798|MT2 } \\
\text { MOUSE }\end{array}$ & Metallothionein-2 & down & 0.727 & 0.65 & 0.689 \\
\hline 34 & $\begin{array}{l}\operatorname{tr} \mid \text { I1E4X1|I1E4X1_ } \\
\text { MOUSE }\end{array}$ & Syntaxin-5 & down & 0.642 & 0.59 & 0.616 \\
\hline 35 & $\begin{array}{l}\operatorname{tr|} \text { Q3UNF3|Q3UNF3 } \\
\text { MOUSE }\end{array}$ & $\begin{array}{l}\text { Acyl-coenzyme A } \\
\text { oxidase }\end{array}$ & down & 0.726 & 0.646 & 0.686 \\
\hline 36 & $\begin{array}{l}\operatorname{tr|Q4VAF0|Q4VAF0~} \\
\text { MOUSE }\end{array}$ & Acylphosphatase & down & 0.87 & 0.613 & 0.742 \\
\hline 37 & $\begin{array}{l}\operatorname{tr}|\mathrm{Q} 3 \mathrm{TXK} 6| \mathrm{Q} 3 \mathrm{TXK} 6 \\
\text { MOUSE }\end{array}$ & $\begin{array}{l}\text { Putative } \\
\text { uncharacterized } \\
\text { protein }\end{array}$ & down & 0.716 & 0.606 & 0.661 \\
\hline 38 & $\begin{array}{l}\operatorname{tr}|\mathrm{G} 3 \mathrm{X} 8 \mathrm{Q} 5| \mathrm{G} 3 \mathrm{X} 8 \mathrm{Q} 5 \\
\text { MOUSE }\end{array}$ & Ceruloplasmin & down & 0.741 & 0.555 & 0.648 \\
\hline 39 & $\begin{array}{l}\operatorname{tr} \mid \text { K4DI77|K4DI77_- } \\
\text { MOUSE }\end{array}$ & $\begin{array}{l}\text { WD repeat-containing } \\
\text { protein } 81\end{array}$ & down & 0.663 & 0.885 & 0.774 \\
\hline 40 & $\begin{array}{l}\operatorname{tr} \mid \text { Q3TVJ0|Q3TVJ0_ } \\
\text { MOUSE }\end{array}$ & $\begin{array}{l}\text { Putative } \\
\text { uncharacterized } \\
\text { protein }\end{array}$ & down & 0.563 & 0.359 & 0.461 \\
\hline
\end{tabular}

(Continued) 


\begin{tabular}{|c|c|c|c|c|c|c|}
\hline Hits & Accession & Protein name & Expression & $114 / 116$ & $119 / 118$ & Mean \\
\hline 41 & $\begin{array}{l}\operatorname{tr}|\mathrm{Q} 1 \mathrm{KYM} 0| \mathrm{Q} 1 \mathrm{KYM} 0 \\
\text { MOUSE }\end{array}$ & Env polyprotein & down & 0.661 & 0.614 & 0.638 \\
\hline 42 & $\begin{array}{l}\operatorname{tr}|\mathrm{Q} 3 \mathrm{THB} 4| \mathrm{Q} 3 \mathrm{THB} 4 \\
\text { MOUSE }\end{array}$ & $\begin{array}{l}\text { L-lactate } \\
\text { dehydrogenase }\end{array}$ & down & 0.565 & 0.348 & 0.457 \\
\hline 43 & $\begin{array}{l}\operatorname{tr}|\mathrm{Q} 3 \mathrm{U} 3 \mathrm{U} 6| \mathrm{Q} 3 \mathrm{U} 3 \mathrm{U} 6 \\
\text { MOUSE }\end{array}$ & $\begin{array}{l}\text { Putative } \\
\text { uncharacterized } \\
\text { protein }\end{array}$ & down & 0.631 & 0.97 & 0.801 \\
\hline 44 & $\begin{array}{l}\text { sp|Q91ZX7|LRP1_ } \\
\text { MOUSE }\end{array}$ & $\begin{array}{l}\text { Pro-low-density } \\
\text { lipoprotein receptor- } \\
\text { related protein } 1\end{array}$ & down & 0.577 & 0.708 & 0.643 \\
\hline 45 & $\begin{array}{l}\operatorname{tr}|\mathrm{Q} 3 \mathrm{U} 2 \mathrm{~K} 1| \mathrm{Q} 3 \mathrm{U} 2 \mathrm{~K} 1 \\
\text { MOUSE }\end{array}$ & $\begin{array}{l}\text { Putative } \\
\text { uncharacterized } \\
\text { protein }\end{array}$ & down & 0.629 & 0.915 & 0.772 \\
\hline 46 & $\begin{array}{l}\text { sp|Q8R180|ERO1A_ } \\
\text { MOUSE }\end{array}$ & $\begin{array}{l}\text { ERO1-like protein } \\
\text { alpha }\end{array}$ & down & 0.674 & 0.602 & 0.638 \\
\hline
\end{tabular}

33 proteins were upregulated and 46 were downregulated. Fold changes in abundance were also observed in two additional independent biological replicates.

Table 2: Top 25 KEGG pathways involving common exosome proteins

\begin{tabular}{lccc}
\hline No. & Pathway & $\begin{array}{c}\text { Proteins with pathway } \\
\text { annotation }\end{array}$ & Pathway ID \\
\hline 1 & Metabolic pathways & $578(15.72 \%)$ & ko01100 \\
2 & RNA transport & $145(3.94 \%)$ & ko03013 \\
3 & Spliceosome & $141(3.84 \%)$ & ko03040 \\
4 & Pathways in cancer & $127(3.45 \%)$ & ko05200 \\
5 & Huntington's disease & $126(3.43 \%)$ & ko05016 \\
6 & Endocytosis & $124(3.37 \%)$ & ko04144 \\
7 & Protein processing in & $122(3.32 \%)$ & ko04141 \\
8 & endoplasmic reticulum & $122(3.32 \%)$ & ko05169 \\
9 & Epstein-Barr virus infection & $117(3.18 \%)$ & ko04810 \\
10 & Regulation of actin & cytoskeleton & ko05010 \\
11 & Alzheimer's disease & $113(3.07 \%)$ & ko04510 \\
12 & Focal adhesion & $106(2.88 \%)$ & ko04010 \\
13 & MAPK signaling pathway & $96(2.61 \%)$ & ko04530 \\
14 & Tight junction & $96(2.61 \%)$ & ko05012
\end{tabular}

(Continued) 


\begin{tabular}{lccc}
\hline No. & Pathway & $\begin{array}{c}\text { Proteins with pathway } \\
\text { annotation }\end{array}$ & Pathway ID \\
\hline 15 & HTLV-I infection & $94(2.56 \%)$ & ko05166 \\
16 & Influenza A & $90(2.45 \%)$ & ko05164 \\
17 & Purine metabolism & $89(2.42 \%)$ & ko00230 \\
18 & Oxidative phosphorylation & $88(2.39 \%)$ & ko00190 \\
19 & Ribosome & $86(2.34 \%)$ & ko03010 \\
20 & Insulin signaling pathway & $82(2.23 \%)$ & ko04910 \\
21 & Ubiquitin mediated & $80(2.18 \%)$ & ko04120 \\
22 & proteolysis & $79(2.15 \%)$ & ko03015 \\
23 & mRNA surveillance pathway & $75(2.04 \%)$ & ko04142 \\
24 & Lysosome & $72(1.96 \%)$ & ko05168 \\
25 & Herpes simplex infection & $70(1.9 \%)$ & ko03008 \\
\hline
\end{tabular}
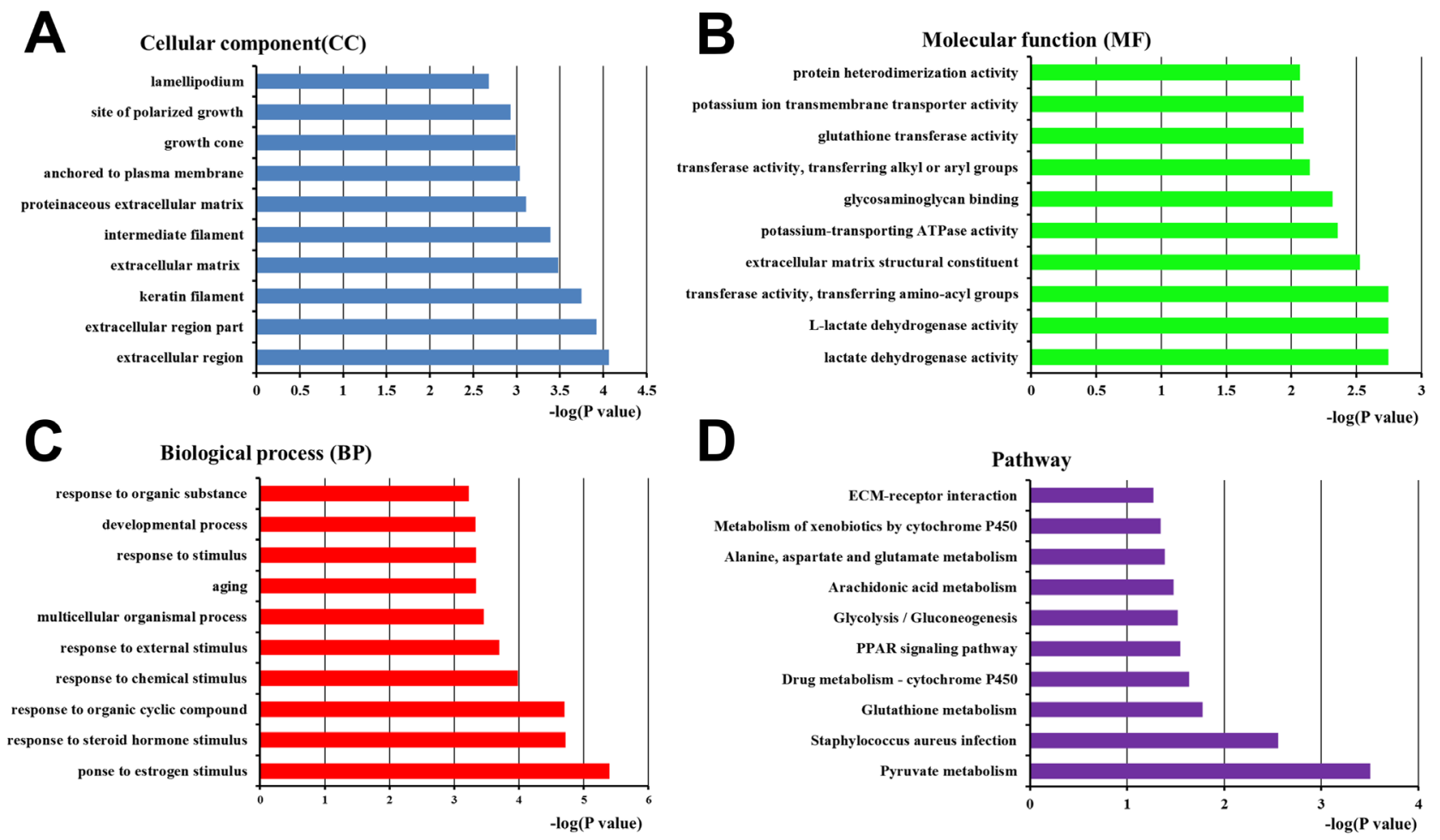

Figure 7: Bioinformatics analysis of proteins differentially expressed between Panc02 EXOs and Panc02-H7 EXOs. $\mathrm{GO}$ annotation of the final selected differentially expressed proteins, and KEGG pathway analysis. Differentially expressed proteins were classified by cellular component (CC). (A), molecular function (MF) (B), biological process (BP) (C), and pathway analysis (D) The top $10 \mathrm{CC}, \mathrm{MF}, \mathrm{BP}$, and pathway analysis components of the selected differentially expressed proteins are shown. Enrichment scores are represented as $-\log (\mathrm{p}$-values). 
Table 3: Selected proteins identified in Panc02 EXOs and Panc02-H7 EXOs via iTRAQ quantitative proteomic analysis

\begin{tabular}{|c|c|c|c|}
\hline Category & Accession & Protein name & ExoCarta \\
\hline ESCRT-1 & $\operatorname{tr}|\mathrm{Q} 3 \mathrm{UK} 08| \mathrm{Q} 3 \mathrm{UK} 08$ _MOUSE & TSG 101 & Yes \\
\hline \multirow[t]{4}{*}{ ESCRT-associated } & sp|Q8R1T1|CHMP7_MOUSE & CHMP7 & Yes \\
\hline & sp|Q9CQ10|CHMP3_MOUSE & CHMP3 & Yes \\
\hline & $\operatorname{tr}|\mathrm{Q} 3 \mathrm{TDX} 2| \mathrm{Q} 3 \mathrm{TDX} 2 \_\mathrm{MOUSE}$ & VPS4A & Yes \\
\hline & sp|Q9WU78|PDC6I_MOUSE & PCD6IP / Alix & Yes \\
\hline \multirow[t]{3}{*}{ Tetraspanins } & sp|Q9CQ88|TSN31_MOUSE & Tetraspanin-31 & No \\
\hline & $\operatorname{tr|Q3UC80|Q3UC80\_ MOUSE~}$ & CD63 antigen & Yes \\
\hline & 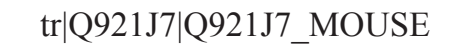 & Tetraspanin/CD151 & Yes \\
\hline Tetraspanins-associated & tr|G3UYZ1|G3UYZ1_MOUSE & IGSFM8 & Yes \\
\hline \multirow[t]{24}{*}{ GTPase } & tr|Q5SW88|Q5SW88_MOUSE & RAB1A & Yes \\
\hline & sp|Q9D1G1|RAB1B_MOUSE & RAB1B & Yes \\
\hline & sp|P53994|RAB2A_MOUSE & RAB2A & Yes \\
\hline & tr|Q6P7T7|Q6P7T7_MOUSE & RAB2B & Yes \\
\hline & $\operatorname{tr|B2RRN5|B2RRN5\_ MOUSE~}$ & RAB4A & Yes \\
\hline & sp|Q9CQD1|RAB5A_MOUSE & RAB5A & Yes \\
\hline & $\operatorname{tr}|\mathrm{Q} 0 \mathrm{PD} 56| \mathrm{Q} 0 \mathrm{PD} 56 \_\mathrm{MOUSE}$ & RAB5B & Yes \\
\hline & $\operatorname{tr}|\mathrm{Q} 8 \mathrm{C} 266| \mathrm{Q} 8 \mathrm{C} 266 \_\mathrm{MOUSE}$ & RAB5C & Yes \\
\hline & $\begin{array}{c}\operatorname{tr}|\mathrm{Q} 3 \mathrm{U} 4 \mathrm{~W} 5| \mathrm{Q} 3 \mathrm{U} 4 \mathrm{~W} 5 \\
\text { MOUSE }\end{array}$ & RAB6 & Yes \\
\hline & sp|P51150|RAB7A_MOUSE & RAB7A & Yes \\
\hline & $\begin{array}{c}\operatorname{tr}|\mathrm{Q} 3 \mathrm{UHW} 5| \mathrm{Q} 3 \mathrm{UHW} \\
\text { MOUSE }\end{array}$ & RAB8A & Yes \\
\hline & sp|P61028|RAB8B_MOUSE & RAB8B & Yes \\
\hline & $\operatorname{tr}|\mathrm{A} 2 \mathrm{AFP} 4| \mathrm{A} 2 \mathrm{AFP} 4$ MOUSE & RAB9A & Yes \\
\hline & sp|P61027|RAB10_MOUSE & RAB10 & Yes \\
\hline & sp|P46638|RB11B_MOUSE & RAB11B & Yes \\
\hline & $\operatorname{tr}|\mathrm{A} 2 \mathrm{CG} 35| \mathrm{A} 2 \mathrm{CG} 35$ MOUSE & RAB12 & Yes \\
\hline & $\operatorname{tr}|\mathrm{Q} 50 \mathrm{HX} 0| \mathrm{Q} 50 \mathrm{HX} 0 \_\mathrm{MOUSE}$ & RAB14 & Yes \\
\hline & sp|P35293|RAB18_MOUSE & RAB18 & Yes \\
\hline & 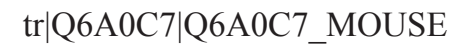 & RAB21 & Yes \\
\hline & $\operatorname{tr} \mid$ A2ARZ7|A2ARZ7_MOUSE & RAB22A & Yes \\
\hline & tr|Q3TXV4|Q3TXV4_MOUSE & RAB22B & Yes \\
\hline & tr|Q9D4I9|Q9D4I9_MOUSE & RAB23 & Yes \\
\hline & $\operatorname{tr}|\mathrm{Q} 0 \mathrm{PD} 20| \mathrm{Q} 0 \mathrm{PD} 20 \_\mathrm{MOUSE}$ & RAB34 & Yes \\
\hline & sp|Q6PHN9|RAB35 MOUSE & RAB35 & Yes \\
\hline
\end{tabular}

(Continued) 


\begin{tabular}{|c|c|c|c|}
\hline Category & Accession & Protein name & ExoCar \\
\hline & $\begin{array}{c}\operatorname{tr} \mid \mathrm{Q} 3 \mathrm{UZM} \text { 8|Q3UZM8_ } \\
\text { MOUSE }\end{array}$ & RAB40C & No \\
\hline Syntenin & sp|Q99JZ0|SDCB2_MOUSE & Syntenin-2 & Yes \\
\hline \multirow[t]{5}{*}{ SNARE } & 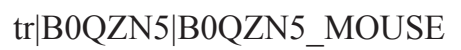 & VSMP 2 & Yes \\
\hline & sp|P63024|VAMP3_MOUSE & VSMP 3 & Yes \\
\hline & $\operatorname{tr} \mid$ Q8BSN6|Q8BSN6_MOUSE & VSMP 4 & No \\
\hline & sp|P70280|VAMP7_MOUSE & VSMP 7 & Yes \\
\hline & sp|O70404|VAMP8_MOUSE & VSMP 8 & Yes \\
\hline \multirow[t]{2}{*}{ Internalization motif } & $\begin{array}{c}\operatorname{tr} \mid \text { A2APM1|A2APM1 } \\
\text { MOUSE }\end{array}$ & CD44 antigen & Yes \\
\hline & sp|Q62351|TFR1_MOUSE & Transferrin receptor protein 1 & Yes \\
\hline Protein binding domain & sp|Q9WV91|FPRP_MOUSE & $\begin{array}{l}\text { Prostaglandin F2 receptor } \\
\text { negative regulator }\end{array}$ & Yes \\
\hline \multirow[t]{4}{*}{ Heat shock protein } & sp|P17879|HS71B_MOUSE & $\begin{array}{l}\text { Heat shock } 70 \mathrm{kDa} \text { protein } \\
1 \mathrm{~B}\end{array}$ & Yes \\
\hline & 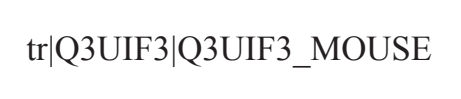 & $\begin{array}{c}\text { Heat shock protein HSP } \\
\text { 90-alpha }\end{array}$ & Yes \\
\hline & $\begin{array}{c}\operatorname{tr}|\mathrm{Q} 3 \mathrm{UBU} 0| \mathrm{Q} 3 \mathrm{UBU} 0_{-} \\
\text {MOUSE }\end{array}$ & Hsp90b1 & Yes \\
\hline & sp|Q61699|HS105_MOUSE & Heat shock protein $105 \mathrm{kDa}$ & Yes \\
\hline \multirow[t]{9}{*}{ Annexin } & tr|Q3U5N9|Q3U5N9_MOUSE & Annexin A1 & Yes \\
\hline & 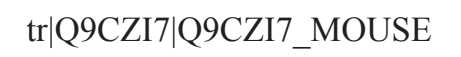 & Annexin A2 & Yes \\
\hline & 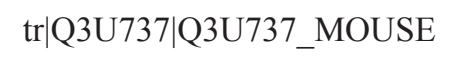 & Annexin A3 & Yes \\
\hline & sp|P97429|ANXA4_MOUSE & Annexin A4 & Yes \\
\hline & sp|P48036|ANXA5_MOUSE & Annexin A5 & Yes \\
\hline & tr|Q3TUI1|Q3TUI1_MOUSE & Annexin A6 & Yes \\
\hline & 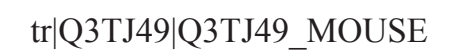 & Annexin A7 & Yes \\
\hline & 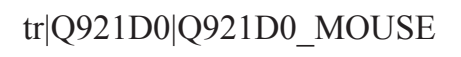 & Annexin A8 & Yes \\
\hline & sp|P97384|ANX11_MOUSE & Annexin A11 & Yes \\
\hline \multirow[t]{8}{*}{ Adhesion } & $\begin{array}{c}\operatorname{tr}|\mathrm{Q} 3 \mathrm{UGY} 5| \mathrm{Q} 3 \mathrm{UGY} 5 \\
\text { MOUSE }\end{array}$ & Fibronectin & Yes \\
\hline & sp|P09055|ITB1_MOUSE & Integrin beta- 1 & Yes \\
\hline & sp|Q62470|ITA3_MOUSE & Integrin alpha-3 & Yes \\
\hline & sp|O54890|ITB3_MOUSE & Integrin beta-3 & Yes \\
\hline & sp|A2A863|ITB4_MOUSE & Integrin beta- 4 & Yes \\
\hline & $\operatorname{tr|}$ & Integrin alpha 5 & Yes \\
\hline & 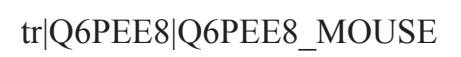 & Integrin alpha-6 & Yes \\
\hline & $\operatorname{tr}|\mathrm{A} 2 \mathrm{AKI} 5| \mathrm{A} 2 \mathrm{AKI} 5 \_\mathrm{MOUSE}$ & Integrin alpha-V & Yes \\
\hline S100 & sp|P07091|S10A4_MOUSE & Protein S100-A4 & Yes \\
\hline
\end{tabular}

(Continued) 


\begin{tabular}{lccc}
\hline Category & Accession & Protein name & ExoCarta \\
\hline sp|P14069|S10A6_MOUSE & Protein S100-A6 & Yes \\
$\operatorname{tr} \mid \mathrm{Q} 3$ UUF30|Q3UF30_MOUSE & Protein S100-A10 & Yes \\
sp|P50543|S10AB_MOUSE & Protein S100-A11 & Yes \\
sp|P97352|S10AD_MOUSE & Protein S100-A13 & Yes \\
sp|P50114|S100B_MOUSE & Protein S100-B & Yes \\
\hline
\end{tabular}

Presence or absence of detected proteins in the ExoCarta database is noted.

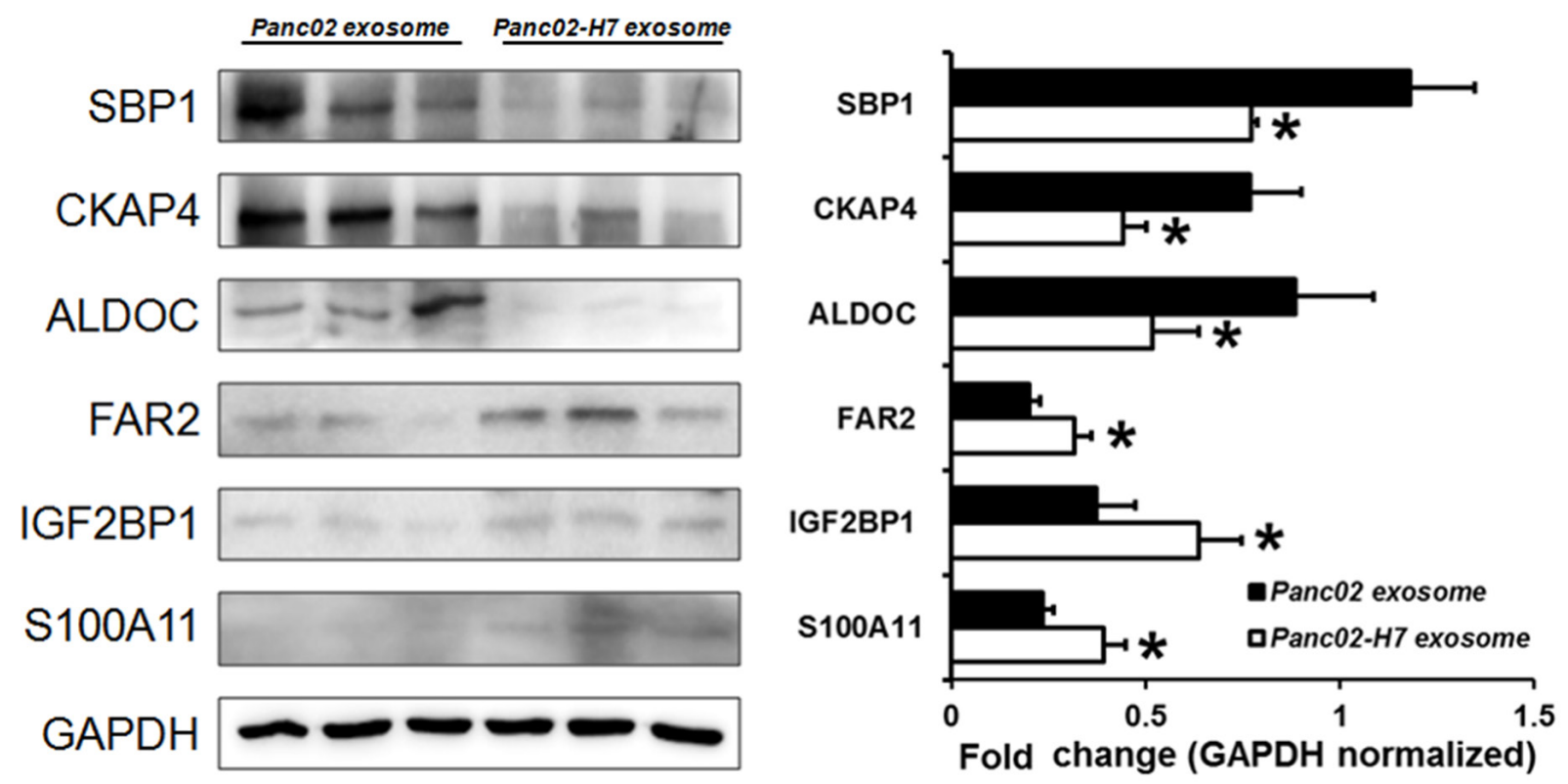

Figure 8: Validation of iTRAQ quantitative proteomic analysis results. Western blotting validated differential expression patterns for six candidate proteins. FAR2, IGF2BP1, and S100A11 were upregulated, and SBP1, CKAP4, and ALDOC were down regulated in Panc02-H7 EXOs compared to Panc02 EXOs, in agreement with iTRAQ results.n=3/group. ${ }^{*} \mathrm{P}<0.05$.

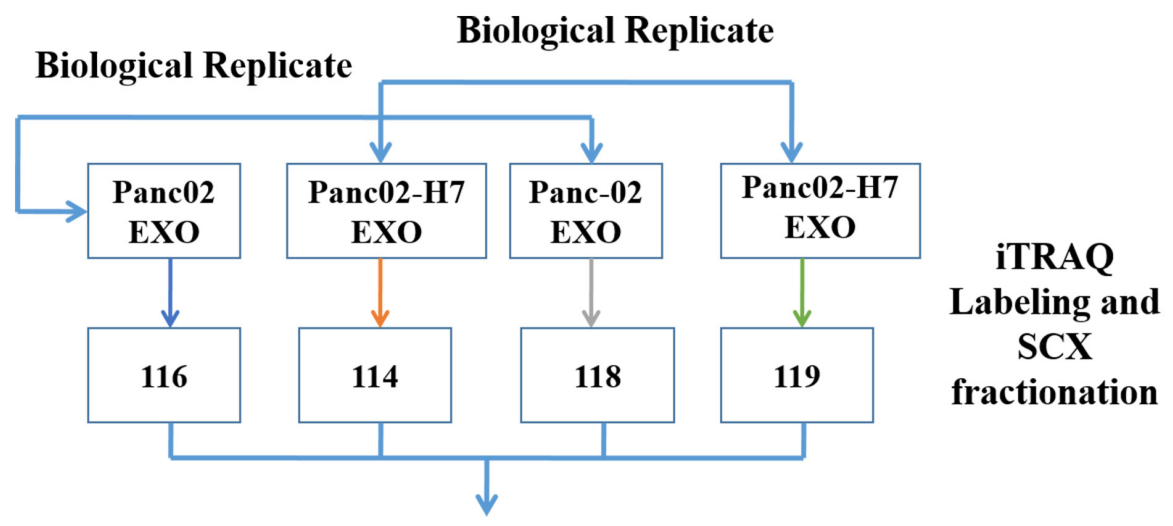

\section{LC-ESI-MS/MS analysis based on Q EXACTIVE}

\section{Database search and bioinformatic analysis}

Figure 9: iTRAQ labeling experimental design schematic. Panc02 and Panc02-H7 cell-derived exosomes (EXO) were labeled with iTRAQ tags, 116 and 114, respectively, and another pair of biological replicates of the same samples was labeled with iTRAQ tags, 118 and 119 , respectively. 
Exosome treatment increased both $\mathrm{CD}_{11 b^{+}}$and $\mathrm{CD} 45^{+}$ hematopoietic progenitor cells in the liver, and activated Stat3 in myeloid cells. Wen, et al. showed that highly metastatic breast cancer-derived exosomes were taken up by CD45 ${ }^{+}$BMDCs [27]. Subsequent conditioning of naïve mice promoted MDSC accumulation and immune suppressive microenvironment formation in the lung and liver. Breast cancer exosomes also directly suppressed T-cell proliferation and inhibited NK cell cytotoxicity, likely suppressing the anti-cancer immune response in pre-metastatic organs [27]. Our results also showed that pancreatic cancer-derived exosomes increased MDSC (CD $11 b^{+} \mathrm{GR} 1^{+}$cells) frequency in peripheral blood after exosome "education."

We found that Panc02-H7 cell-derived exosomes induced liver pre-metastatic niche formation in naïve mice and consequently increased primary tumor growth and liver metastatic burden. We then identified exosomal proteins from Panc02 and Panc02-H7 cells via iTRAQbased quantitative proteomic analysis. iTRAQ is currently one of the most robust methods of peptide labeling-based protein quantification. Our study identified more proteins than previous exosome proteomic studies [28-29], and nearly all of the 25 proteins most frequently identified in the ExoCarta databank as exosomal markers (http:// exocarta.org/exosome_markers).

The profuse desmoplastic stroma forces pancreatic cancer cells to adapt their metabolisms to the hostile microenvironment. Metabolic reprogramming is essential for cancer cell survival and optimized growth in metastatic site microenvironments [30-31], and was recently recognized as a pancreatic cancer hallmark [32]. Cancer cell metabolic reprogramming may be a key pancreatic cancer progression and metastasis driver. Pathway analysis of differentially expressed proteins revealed that exosomal proteins are related to metabolism and cancer-related signaling pathways, including pyruvate metabolism, glutathione metabolism, glycolysis/gluconeogenesis, and alanine, aspartate, and glutamate metabolism.

In conclusion, our analyses demonstrated that metabolism-related signaling pathways were involved in exosome-mediated intracellular communication. We found that Panc02-H7-derived exosomes reduced Panc02 cell adhesion, and increased migration and invasion, enhancing the metastatic nature of these cells. In a mouse model, Panc02-H7 exosomes induced liver pre-metastatic niche formation and promoted primary tumor growth and liver metastasis. Further studies are needed to confirm whether the exosome-specific proteins identified in our bioinformatics studies are potential candidate pancreatic cancer diagnostic/ prognostic markers or novel therapeutic targets.

\section{MATERIALS AND METHODS}

\section{Chemicals and reagents}

RPMI 1640, fetal bovine serum (FBS), proteases, proteases inhibitors, and antibiotics were purchased from
Gibco-BRL (Shanghai, China). PKH67 membrane dye and 5-(N, N-Dimethyl) amiloride hydrochloride (DMA) were purchased from Sigma-Aldrich (MO, USA).Trans-well chambers were purchased from Corning Life Sciences (MA, USA). All iTRAQ reagents and buffers were purchased from Applied Biosystems, Inc. (Foster City, CA). All other reagents were of the highest analytical grades available and unless otherwise stated were purchased from Sigma-Aldrich (MO, USA).

\section{Cell lines and cultures}

Corbett, et al. originally established the Panc02 murine PDAC cell line [33]. Wang, et al. established the Panc02-H7 sub-line using an in vivo selection method [11]. Panc02-H7cells are highly aggressive after implantation, with progressive growth in the pancreas, peritoneal dissemination, and distant metastasis to multiple organs, including the liver and lungs. All cell lines were gifted from Dr. Min Li (M.D. Anderson Cancer Center, USA). Cells were maintainedin RPMI 1640 supplemented with $10 \%$ heat-inactivated FBS, 100 units/ml penicillin, $100 \mathrm{mg} / \mathrm{ml}$ streptomycin, and $0.25 \mathrm{mg} / \mathrm{ml}$ amphotericin B, and incubated at $37^{\circ} \mathrm{C}$ in humidified air with $5 \% \mathrm{CO}_{2}$.

\section{Mice}

Female C57BL/6 mice were purchased from Nanjing Chinchilla Technology Co. Ltd. (Nanjng, China) and used at 4-6 weeks of age. Animal experiments abided by the Guidelines for Animal Care and Use issued by the Southeast University Medical School Institutional Animal Care and Use Committee.

\section{Exosome isolation and purification}

Panc02 and Panc02-H7cells were cultured to $70 \%$ confluence in $75 \mathrm{~cm}^{2}$ flasks in RPMI-1640medium supplemented with $10 \%$ exosome-free FBS, which had been depleted of bovine-derived exosomes by ultracentrifugation for $70 \mathrm{~min}$ at $100,000 \mathrm{~g}$, followed by filtration through a $0.2-\mu \mathrm{m}$ filter from Millipore (MA, USA). Supernatants collected from flasks were pelleted by centrifugation at $500 \mathrm{~g}$ for $10 \mathrm{~min}$ and 2,000 $\mathrm{g}$ for $20 \mathrm{~min}$, resulting in floating cells and cell debris, respectively, and then further centrifuged at 20,000 $\mathrm{g}$ for $30 \mathrm{~min}$ to pellet larger microvesicles (MVs). Crude exosomes were prepared via ultracentrifugation of the supernatant at $100,000 \mathrm{~g}$ for $70 \mathrm{~min}$, washing in PBS, and pelleting again by ultracentrifugation at 100,000 g for $70 \mathrm{~min}$. Ultracentrifugation was always performed at $4^{\circ} \mathrm{C}$. Crude exosome pellets were resuspended in $1 \mathrm{ml}$ PBS and then filtered $(0.22 \mu \mathrm{m})$. Purified exosomes were obtained as previously described with minor modification [28]. Briefly, PBS-suspended exosome preparations were diluted in $3.5 \mathrm{ml} \mathrm{PBS}$ and layered on top of a density cushion composed of $20 \mathrm{mM}$ Tris/30\% sucrose/ 
deuteriumoxide $\left(\mathrm{D}_{2} \mathrm{O}\right) / \mathrm{HCL} \mathrm{pH} 7.35(0.5 \mathrm{ml})$ forming a visible interphase. Samples were ultracentrifuged at $100,000 \mathrm{~g}$ for $70 \mathrm{~min}$. Exosomes contained in the 30\% sucrose $/ \mathrm{D}_{2} \mathrm{O} /$ Tris cushion and interphase were diluted five times with PBS and centrifugedat $120,000 \mathrm{~g}$ for $70 \mathrm{~min}$. The final exosome pellets (Panc02 EXO and Panc02-H7 EXO) of higher purity were resuspended in PBS. We measured purified exosome total protein concentrations using the Bradford assay (Bio-Rad Laboratories, Hercules, CA), and purified exosome were stored at $-80^{\circ} \mathrm{C}$ until use.

\section{Transmission electron microscopy (TEM)}

Purified exosomes were fixed in 2\% paraformaldehyde $(\mathrm{w} / \mathrm{v})$ in $200 \mathrm{mM}$ phosphate buffer (pH 7.4). Fixed exosomes were dripped onto Formvar carbon-coated 200 mesh copper grids and absorbed at roomtemperature (RT) for $10 \mathrm{~min}$. Excess liquid was removed with filter paper. Adsorbed exosomes were negatively stained with $3 \%$ phosphotungstic acid at RT for $5 \mathrm{~min}$, dried with an incandescent lampfor 2 min, and observed viaTEM (JEM-2010; JEOL, Ltd., Tokyo, Japan) operating at $80.0 \mathrm{kV}$. Images were obtained using a cooled slow CCD camera.

\section{Western blotting}

Exosome, cell, and liver tissue protein concentrations were measured with the Bradford assay. Proteins were separated by sodium dodecyl sulfate polyacrylamide gel electrophoresis (SDS-PAGE) and then transferred to polyvinylidine difluoride (PVDF) membranes. Membranes were incubated with primary antibodies at $4^{\circ} \mathrm{C}$ overnight in a buffer containing 5\% skim milk, and then with a horseradish peroxidase (HRP)-conjugated secondary antibody at $37^{\circ} \mathrm{C}$ for $2 \mathrm{~h}$. For exosome validation, primary antibodies against TSG101 (1:1000), CD9 (1:1000), MHC-1 (1:1000), and Cytochrome C (1:1000) were purchased from Abcam (Cambridge, UK). For cell migration and invasion assays, primary antibodies against CXCR4(1:500) and MMP-9 (1:500) were purchased from Boster (Wuhan, China). For liver pre-metastatic niche formation assays, primary antibodies against CD11b (1:1000), S100A8(1:1000), and S100A9 (1:1000) were purchased from Santa Cruz (CA, USA). For MS-identified candidates, primary antibodies against FRA2 (1:1000), IGF2BP2 (1:1000), and S100A11 (1:1000) were purchased from Abcam (Cambridge, UK). Selenium binding protein 1(SBP1, 1:500), CKAP4 (1:500), and aldolase C (ALDOC,1:500) were purchased from Bioss(Beijing, China). Protein-band densities were analyzed quantitatively using ImageJ software (NIH, USA).

\section{Exosome fluorescent labeling and uptake assay}

Exosomes were stained following the manufacturer's instructions. Briefly, Panc02-H7 EXOswere labeled using the green lipophilic fluorescent dye, PKH67 (SigmaAldrich, St. Louis, MO) for $5 \mathrm{~min}$. The reaction was terminated via addition of exosome-free FBS. To remove excess dye, PKH67-labeled exosomes were pelleted at $100,000 \mathrm{~g}$ for $70 \mathrm{~min}$, washed three times with PBS, and resuspended in RPMI- 1640 medium.Panc02 cells were inoculated in 6-well plates with exosome-free medium for $24 \mathrm{~h}$. Cells were incubated with labeled exosomes for $5 \mathrm{~h}$, washed three times with PBS, fixed with $4 \%$ paraformaldehyde for $15 \mathrm{~min}$, and mounted with DAPI nuclear stain (1:100, Life Technologies, Grand Island, NY). Images were obtained using an inverted fluorescence microscope (Carl Zeiss, Germany).

\section{MTT cell adhesion, wound-healing, and invasion assays}

For the cell adhesion assay, 96-well plates from Thermo Scientific (Shanghai China) were incubated at $37^{\circ} \mathrm{C}$ with Matrigel for $1 \mathrm{~h}$ and then terminated with PBS containing 1\% BSA overnight. After exposure to PBS (control group), $100 \mu \mathrm{g} / \mathrm{ml}$ Panc02-H7 EXOs (EXO group), or $7 \mathrm{mmol} / \mathrm{L}$ amiloride (exosomes-depression, Exo-D group), for $24 \mathrm{~h}$, Panc02 cells were suspended in serumfree medium. A Panc 02 cell suspension $\left(1 \times 10_{4}\right.$ cells $\left./ 100 \mu l\right)$ was then added to each well and incubated at $37^{\circ} \mathrm{C}$ for 3 h. Plates were washed three times with PBS to remove unattached cells. Remaining Panc02 cells were reacted with MTT $(5 \mathrm{mg} / \mathrm{ml})$ for $4 \mathrm{~h}$ at $37^{\circ} \mathrm{C}$, then dissolved in DMSO. The absorbance of each well was measured with ELX800 Absorbance Microplate Reader (Bio-TEK Co, Winooski,VT,USA) at $490 \mathrm{~nm}$. OD values represent the number of adherent cells.

For the wound-healing assay, approximately $1 \times 10^{5}$ Panc02 cells were inoculated in 6-well plates. After cultures reached $60 \%$ confluence, the monolayer was scratched using a $100 \mu \mathrm{l}$ pipette tip. Attached cells were washed twice with PBS and incubated with medium as described for the cell adhesion assay. Each group (control, EXO, and Exo-D) was cultured in triplicate. Wound healing was analyzed under a microscope and images were captured at 0 and $24 \mathrm{~h}$. The denuded area was measured viaImageJ (http://rsbweb.nih.gov). Cell motility was quantified using the formula: $\%$ of recovery $=$ $\left(A_{t=0}-A_{t=24}\right) / A_{t=0} \times 100 \%\left(A_{t=0}\right.$ is the denuded area measured immediately after wounding, $\mathrm{A}_{t=24}$ is the denuded area measured $24 \mathrm{~h}$ after incubation). After the experiment, cells were harvested and protein was extracted for Western-blot analysis.

For the Boyden chamber (invasion) assay, Panc02 cells were divided into three groups and pretreated for $24 \mathrm{~h}$ as described adhesion assay. Cells $\left(5 \times 10^{4}\right)$ were harvested and inoculated into upper transwell chambers in 5\% FBS RPMI-1640 medium. 20\% FBS RPMI-1640 medium was added into the lower chamber. Following $24 \mathrm{~h}$ incubation, chamber upper surfaces were wiped with 
cotton swabs, and invading cells were fixed and stained with crystalviolet. Invading cells were counted in three randomly selected microscope fields for each transwell.

\section{Tissue distributions of pancreatic cancer-derived exosomes}

Purified exosomes were labeled using PKH67 as previously described. PKH67-labeled exosomes from Panc02 and Panc02-H7 cells were injected intravenously into syngeneic C57B/L6 mice (20 $\mu \mathrm{g}$ exosomes/mouse). At 24 hpi, liver, lung, spleen, kidney, brain, and bone marrow tissues were harvested. Bone marrow cells were flushed from both the tibia and femurfor confocal microscopy. As controls, mice were injected with equivalent particle numbers of PKH67-labeled synthetic $100 \mu \mathrm{m}$ unilamellar liposomes. Fluorescence intensity was quantified using IPP6.0software (Media Cybernetics) to assess PKH67labeled exosometissue distributions.

\section{Exosome-induced liver pre-metastatic niche formation assessment}

Panc02-H7- and Panc02-derived exosomes (10 $\mu \mathrm{g}$ each) were injected intravenously (tail vein) into C57B/ L6 mice every other day. PBS was used as a control. At $12 \mathrm{~d}$ post-injection (dpi), livers were harvested for IF and Western blotting analysis. Peripheral blood obtained from mice was assessed using flow cytometry.

\section{Exosome-induced pancreatic cancer growth and liver metastasis assessment}

We established a pancreatic-cancer SOI metastatic model with Panc02 cells in C57BL/6 mice as described in our previous study [33]. Panc02-H7 EXOs and Panc02 EXOs $(10 \mu \mathrm{g})$ were injected intravenously (tail vein) into C57B/L6 mice three days per week, starting one week following SOI and continuing for three weeks. Mice were sacrificed 15 and $30 \mathrm{~d}$ after SOI. After anesthesia (isoflurane), mice were examined via laparotomy and thoracotomy. All solid organs were harvested and stained with hematoxylin and eosin (H\&E) to assess metastases. Liver tissue was further assessed via IHC and Masson's trichrome staining to determine liver metastatic niche changes. Primary tumor volume was calculated using the formula: $\mathrm{V}=0.5 \times \mathrm{a} \times \mathrm{b}^{2}$, where $\mathrm{a}$ and $\mathrm{b}$ represent the long and short diameters of the tumor, respectively. PBS was used as a control.

\section{H\&E staining, IHC, IF, and Masson's trichrome staining}

Tumors and tissues were fixed in 10\% neutral buffered formalin at least one $\mathrm{d}$ before paraffin embedding. Serial $4 \mu \mathrm{m}$ sections were cut and stained with H\&E for histopathological examination. Two pathologists independently counted the number of neutrophils in 10 high power fields.

IHC analysis was performed on formalin-fixed, paraffin-embedded tissue sections. Deparaffinization, antigen retrieval, and antigen-antibody reactions were performed using an automated DAKO Envision with Dual Link system-HRP. Tissue sections were incubated with primary antibodies followed by HRP-conjugated secondary antibody (from DAKO envision kit). Primary antibodies against fibronectin (1:100), $\alpha$-SMA (1:50), S100A8 (1:50), S100A9 (1:50), and F4/80 (1:50) were purchased from Proteintech (Wuhan, China). Stain was developed using diamino-benzidine and counterstained with haematoxylin. IHC analyses were evaluated by two pathologists.

For IF, murine liver tissues were embedded in optimal cutting temperature (OCT) medium and stored at $-80^{\circ} \mathrm{C}$. Tissue sections were fixed in ice-cold acetone, permeabilized in PBS with $0.1 \%$ Triton X-100, blocked in PBS with $8 \%$ normal goat serum, and stained with primary antibodies to CD11b (1:500), P-STAT3 (1:500), CD45 (1:500), fibronectin (1:500), or $\alpha$-SMA (1:500) (Santa Cruz). Tissue sections were then washed in PBS, stained with secondary antibodies conjugated to AlexaFluor 488 or AlexaFluor 594 (1:500, Life Technologies) and counter stained with DAPI (1:100, Life Technologies) to detect nuclei. Images were obtained with fluorescence microscopy (Olympus, BX43).

Masson's trichrome staining for connective tissue was performed according to the manufacturer's instructions (Abcam). IHC, IF, and Masson's trichrome staining images were processed and analyzed via IPP6.0 software (Media Cybernetics).

\section{Flow cytometry and antibodies}

Peripheral blood was obtained by retro-orbital bleeding directly into EDTA anticoagulant tubes (Sarstedt, Newton, NC). Red blood cells were lysed using ACK lysis buffer (Gibco-BRL, Shanghai, China). Fc-receptors were blocked using anti-CD16/CD32 (BD Bioscience, Bedford, MA) before cell suspensions were incubated with fluorochrome-conjugated antibodies (mouse-CD11bFITC and mouse-Ly-6G (Gr-1) PE, eBioscience, CA, USA) diluted in PBS with 1\% BSA. Flow cytometry was performed using a Cytomics FC 500 flow cytometer (Beckman Coulter). Datawere analyzed using FlowJo software (TreeStar, Ashland, OR, USA).

\section{Protein preparation for quantitative proteomic analysis of pancreatic cancer-derived exosomes}

Exosomes were suspended in lysis buffer (7 M urea, $2 \mathrm{M}$ thiourea, 4\%CHAPS, $40 \mathrm{mM}$ Tris- $\mathrm{HCl}$, $\mathrm{pH} 8.5,1 \mathrm{mM}$ PMSF, 2mM EDTA), and sonicated in ice. Proteins were reduced with $10 \mathrm{mM}$ DTT (final 
concentration) at $56^{\circ} \mathrm{C}$ for $1 \mathrm{~h}$ and then alkylated with $55 \mathrm{mM}$ IAM (final concentration) in the dark for $1 \mathrm{~h}$. The reduced and alkylated protein mixtures were precipitated by adding $4 \times$ volume of chilled acetone at $-20^{\circ} \mathrm{C}$ overnight. After centrifugation at $4^{\circ} \mathrm{C}$ and $30,000 \mathrm{~g}$, the pellet was dissolved in 0.5 M TEAB (Applied Biosystems, Milan, Italy) and sonicated in ice. After centrifuguation at $30,000 \mathrm{~g}$ and $4^{\circ} \mathrm{C}$, the supernatant protein concentration was measured with the Bradford assay. Proteins in the supernatant were stored at $-80^{\circ} \mathrm{C}$ until use.

\section{iTRAQ labeling and strong cation exchange fractionation}

Protein $(100 \mu \mathrm{g})$ from each exosome sample was digested with Trypsin Gold (Promega, Madison, WI, USA) at a $30: 1$ protein:trypsin ratio, at $37^{\circ} \mathrm{C}$ for 16 $\mathrm{h}$, and then dried by vacuum centrifugation. Peptides werereconstituted in $0.5 \mathrm{M}$ TEAB and processed according to the manufacturer's protocol for 4-plex iTRAQ reagent.Briefly, one unit of iTRAQ reagent was thawed and reconstituted in $24 \mu$ isopropanol. Samples were labeled with iTRAQ tags as follows: Panc02 EXO and Panc02-H7 EXO were labeled with iTRAQ tags, 116 and 114, respectively, and biological replicates of the same exosomes were labeled with iTRAQ tags, 118 and 119 , respectively. Peptides were labeled with the isobaric tags, incubated at room temperature for $2 \mathrm{~h}$, and then pooled and dried by vacuum centrifugation. Strong cation exchange (SCX) chromatography was performed with a LC-20AB HPLC pump system (Shimadzu, Kyoto, Japan). iTRAQ-labeled peptide mixtures were reconstituted with $4 \mathrm{ml}$ buffer $\mathrm{A}$ ( $25 \mathrm{mM} \mathrm{NaH}_{2} \mathrm{PO}_{4}$ in $25 \% \mathrm{ACN}, \mathrm{pH} 2.7$ ) and loaded onto a $4.6 \times 250 \mathrm{~mm}$ Ultremex SCX column containing $5 \mu \mathrm{m}$ particles. Peptides were eluted at a flow rate of $1 \mathrm{ml} / \mathrm{min}$ with a gradient of buffer A for $10 \mathrm{~min}$, $5-60 \%$ buffer $\mathrm{B}\left(25 \mathrm{mM} \mathrm{NaH} \mathrm{PO}_{4}, 1 \mathrm{M} \mathrm{KCl}\right.$ in $25 \%$ $\mathrm{ACN}, \mathrm{pH} 2.7$ ) for $27 \mathrm{~min}$, and $60-100 \%$ buffer $\mathrm{B}$ for $1 \mathrm{~min}$. The system was then maintained at $100 \%$ buffer $\mathrm{B}$ for $1 \mathrm{~min}$ before equilibrating with buffer $\mathrm{A}$ for 10 min prior to the next injection. Elution was monitored by measuring the absorbance at $214 \mathrm{~nm}$, and fractions were collected every $1 \mathrm{~min}$. Eluted peptides were pooled into 20 fractions, de-salted with a Strata X C18 column (Phenomenex), and vacuum-dried. The iTRAQ workflow is shown in Figure 9.

\section{LC-ESI-MS/MS analysis based on $Q$ EXACTIVE}

Each fraction was resuspended in buffer A $(2 \%$ $\mathrm{ACN}, 0.1 \% \mathrm{FA}$ ) and centrifuged at $20,000 \mathrm{~g}$ for 10 min. The average final peptide concentration was approximately $0.5 \mu \mathrm{g} / \mu \mathrm{l}$. $10 \mu \mathrm{l}$ supernatant was loaded on an LC-20AD nanoHPLC (Shimadzu, Kyoto, Japan) with the autosampler onto a 2-cm C18 trap column. Peptides were eluted onto a 10-cm analytical C18 column packed in-house. Samples were loaded at $8 \mu \mathrm{l} / \mathrm{min}$ for $4 \mathrm{~min}$, and then the 44-min gradient was run at $300 \mathrm{nl} / \mathrm{min}$ from $2-35 \%$ B (98\%ACN, 0.1\%FA) followed by a 2-min linear gradient to $80 \% \mathrm{~B}$, maintenance at $80 \% \mathrm{~B}$ for $4 \mathrm{~min}$, and a return to $5 \%$ over $1 \mathrm{~min}$. Peptides were subjected to nano-electrospray ionization followed by tandem mass spectrometry (MS/MS) in a QEXACTIVE (Thermo Fisher Scientific, San Jose, CA) coupled online to the HPLC. Intact peptides were detected in the Orbitrap at a resolution of 70,000. Peptides were selected for MS/MS using the high-energy collision dissociation (HCD) operating mode with a normalized collision energy setting of 27.0. Ion fragments were detected in the Orbitrap at a resolution of 17,500. A data-dependent procedure that alternated between one MS scan followed by $15 \mathrm{MS} / \mathrm{MS}$ scans was applied for the 15 most abundant precursor ions above a threshold ion count of 20,000 in the MS survey scan, with a following Dynamic Exclusion duration of $15 \mathrm{~s}$. The electrospray voltage applied was $1.6 \mathrm{kV}$. Automatic gain control (AGC) was used to optimize the spectra generated by the Orbitrap. The AGC target for full MS was 3e6, and 1e5 for MS2. The $\mathrm{m} / \mathrm{z}$ scan ranges were 350-2,000 Da for MS scans, and 100-1800Da for MS2 scans.

\section{MS data analysis}

Raw data files acquired from the Orbitrap were converted into MGF files using Proteome Discoverer 1.2 (PD 1.2, Thermo) (5600 ms converter) and the MGF files were searched. Protein identification was performed using the Mascot search engine (Matrix Science, London, UK; version 2.3.02) against uniprot+exosome (mouse) databases containing 78,156 sequences. For protein identification, a mass tolerance of $10 \mathrm{ppm}$ was permitted for intact peptide masses and $0.05 \mathrm{Da}$ for fragmented ions, with allowance for one missed cleavage in the trypsin digest. Gln->pyro-Glu (N-term Q), oxidation (M), and Deamidated (NQ) were the potential variable modifications, and Carbamidomethyl (C), iTRAQ 4 plex (N-term), and iTRAQ 4 plex $(\mathrm{K})$ were fixed modifications. Peptide charge states were set to +2 and +3 . An automatic decoy database search was performed in Mascot by choosing the decoy checkbox, in which a random database sequence is generated and tested for raw spectra as well as the real database. To reduce the probability of false peptide identification, only peptides at the $95 \%$ confidence interval as determined by a Mascot probability analysis greater than "identity" were counted as identified. Each protein identification involved at least one unique peptide. Protein quantitation required that a given protein contain at least two unique spectra. Quantitative protein ratios were weighted and normalized by the median ratio in Mascot. We only used ratios with $\mathrm{p}<0.05$, and only fold changes of $>1.5$ were considered significant. 


\section{Bioinformatics analyses}

Protein functional annotations were conducted using Blast2GO against the non-redundant protein database (NR;NCBI). The KEGG database (http://www.genome. $\mathrm{jp} / \mathrm{kegg} /$ ) was used to classify and group these identified proteins. Gene Ontology (GO) is an international standardization of gene function classification system. It provides a dynamically-updated, controlled vocabulary to describe gene and gene product attributes in the organism. GO ontologies describe molecular function, cellular component, and biological process. KEGG PATHWAY is a collection of manually drawn pathway maps representing molecular interaction and reaction networks.

\section{Statistical analysis}

Quantitative data are presented as means \pm standard error of the mean (s.e.m.). Statistical analyses were performed using SPSS software, version 18.0. Data were compared using Student's $t$-test. $\mathrm{P}<0.05$ was considered significant. For functional enrichment analysis using DAVID, cluster with an enrichment score $>1.3(-\log (\mathrm{p}-$ value)) were considered significant (the geometric mean of the p-values in a significant cluster was $<0.05$ ).

\section{CONFLICTS OF INTEREST}

The authors declare no conflicts of interest.

\section{GRANT SUPPORT}

We thank the the National Natural Science Foundation of China (program no. 81071967, 81502505 and 81572408 ) for financial support.

\section{REFERENCES}

1. Siegel RL, Miller KD, Jemal A. Cancer statistics,2016. CA Cancer J Clin.2016; 66:7-30.

2. Chen W, Zheng R, Baade PD, Zhang S, Zeng H, Bray F, Jemal A, Yu XQ, He J. Cancer statistics in China, 2015. CA Cancer J Clin.2016; 66:115-132.

3. Spinelli GP, Zullo A, Romiti A, Di Seri M, Tomao F, Miele E, Spalletta B, Eramo A, Hassan C, Tomao S. Long-term survival in metastatic pancreatic cancer. A case report and review of the literature. JOP. 2006; 7:486-491.

4. Suetsugu A, Honma K, Saji S, Moriwaki H, Ochiya T, Hoffman RM. Imaging exosome transfer from breast cancer cells to stroma at metastatic sites in orthotopic nude mouse models. Adv. Drug Deliv. Rev. 2013; 65:383-390.

5. Peinado H, Lavotshkin S, Lyden D. The secreted factors responsible for pre-metastatic niche formation: old sayings and new thoughts. Semin Cancer Biol. 2011; 21:139-146.
6. Melo SA, Luecke LB, Kahlert C, Fernandez AF, Gammon ST, Kaye J, LeBleu VS, Mittendorf EA, Weitz J, Rahbari N, Reissfelder C, Pilarsky C, Fraga MF, Piwnica-Worms D, Kalluri R. Glypican-1 identifies cancer exosomes and detects early pancreatic cancer. Nature.2015; 523:177-182.

7. Lau C, Kim Y, Chia D, Spielmann N, Eibl G, Elashoff D, Wei F, Lin YL, Moro A, Grogan T, Chiang S, Feinstein E, Schafer C, Farrell J, Wong DT. Role of pancreatic cancerderived exosomes in salivary biomarker development. J Biol Chem.2013;288:26888-26897.

8. Costa-Silva B, Aiello NM, Ocean AJ, Singh S, Zhang H, Thakur BK, Becker A, Hoshino A, Mark MT, Molina H, Xiang J, Zhang T, Theilen TM, García-Santos G, Williams C, Ararso Y, Huang Y, Rodrigues G, Shen TL, Labori KJ, Lothe IM, Kure EH, Hernandez J, Doussot A, Ebbesen SH, Grandgenett PM, Hollingsworth MA, Jain M, Mallya K, Batra SK, Jarnagin WR, Schwartz RE, Matei I, Peinado H, Stanger BZ, Bromberg J, Lyden D. Pancreatic cancer exosomes initiate pre-metastatic niche formation in the liver. Nat Cell Biol. 2015; 17:816-826.

9. Madhavan B, Yue S, Galli U, Rana S, Gross W, Müller M, Giese NA, Kalthoff H, Becker T, Büchler MW, Zöller M. Combined evaluation of a panel of protein and miRNA serum-exosome biomarkers for pancreatic cancer diagnosis increases sensitivity and specificity. Int J Cancer. 2015;136:2616-2627.

10. Adamczyk KA, Klein-Scory S, Tehrani MM, Warnken U, Schmiegel W, Schnölzer M, Schwarte-Waldhoff I. Characterization of soluble and exosomal forms of the EGFR released from pancreatic cancer cells. Life Sci. 2011; 89:304-312.

11. Wang B, Shi Q, Abbruzzese JL, Xiong Q, Le X, Xie K. A novel, clinically relevant animal model of metastatic pancreatic adenocarcinoma biology and therapy. Int $\mathrm{J}$ Pancreatol. 2001; 29:37-46.

12. Chalmin F, Ladoire S, Mignot G, Vincent J, Bruchard M, Remy-Martin JP, Boireau W, Rouleau A, Simon B, Lanneau D, De Thonel A, Multhoff G, Hamman A, Martin F, Chauffert B, Solary E, Zitvogel L, Garrido C, Ryffel B, Borg C, Apetoh L, Rébé C, Ghiringhelli F. Membraneassociated Hsp72 from tumor-derived exosomes mediates STAT3-dependent immunosuppressive function of mouse and human myeloid-derived suppressor cells. J Clin Invest. 2010; 120:457-471.

13. Jeppesen DK, Nawrocki A, Jensen SG, Thorsen K, Whitehead B, Howard KA, Dyrskjøt L, Ørntoft TF, Larsen MR, Ostenfeld MS. Quantitative proteomics of fractionated membrane and lumen exosome proteins from isogenic metastatic and nonmetastatic bladder cancer cells reveal differential expression of EMT factors. Proteomics.2014; 14:699-712.

14. Azmi AS, Bao B, Sarkar FH. Exosomes in cancer development, metastasis, and drug resistance: a comprehensive review. Cancer Metastasis Rev. 2013; 32:623-642. 
15. Jung T, Castellana D, Klingbeil $\mathrm{P}$, Cuesta Hernández I, Vitacolonna M, Orlicky DJ, Roffler SR, Brodt P, Zöller M. CD44v6 dependence of premetastatic niche preparation by exosomes. Neoplasia. 2009; 11:1093-1105.

16. Peinado H, Alečković M, Lavotshkin S, Matei I, CostaSilva B, Moreno-Bueno G, Hergueta-Redondo M, Williams C, García-Santos G, Ghajar C, Nitadori-Hoshino A, Hoffman C, Badal K, Garcia BA, Callahan MK, Yuan J, Martins VR, Skog J, Kaplan RN, Brady MS, Wolchok JD, Chapman PB, Kang Y, Bromberg J, Lyden D. Melanoma exosomes educate bone marrow progenitor cells toward a pro-metastatic phenotype through MET. Nat Med.2012; 18:883-91.

17. Raman D, Baugher PJ, Thu YM, Richmond A. Role of chemokines in tumor growth. Cancer Lett. 2007; 256:137-165.

18. Xu Q, Wang Z, Chen X, Duan W, Lei J, Zong L, Li X, Sheng L, Ma J, Han L, Li W, Zhang L, Guo K, Ma Z, Wu Z, Wu E, Ma Q. Stromal-derived factor-1 $\alpha /$ CXCL12CXCR4 chemotactic pathway promotes perineural invasion inpancreatic cancer.Oncotarget.2015; 6:4717-4732.

19. Zhang W, Liu Y, Wang CW. S100A4 promotes squamous cell laryngeal cancer Hep-2 cell invasion via NF-kB/ MMP-9 signal. Eur Rev Med Pharmacol Sci. 2014; 18:1361-1367.

20. Hoshino A, Costa-Silva B, Shen TL, Rodrigues G, Hashimoto A, Tesic Mark M, Molina H, Kohsaka S, Di Giannatale A, Ceder S, Singh S, Williams C, Soplop N, Uryu K, Pharmer L, King T, Bojmar L, Davies AE, Ararso Y, Zhang T, Zhang H, Hernandez J, Weiss JM, Dumont-Cole VD, Kramer K, Wexler LH, Narendran A, Schwartz GK, Healey JH, Sandstrom P, Labori KJ, Kure EH, Grandgenett PM, Hollingsworth MA, de Sousa M, Kaur S, Jain M, Mallya K, Batra SK, Jarnagin WR, Brady MS, Fodstad O, Muller V, Pantel K, Minn AJ, Bissell MJ, Garcia BA, Kang Y, Rajasekhar VK, Ghajar CM, Matei I, Peinado H, Bromberg J, Lyden D. Tumour exosome integrinsdetermine organotropic metastasis.Nature.2015; 527:329-335.

21. Nielsen SR, Quaranta V, Linford A, Emeagi P, Rainer C, Santos A, Ireland L, Sakai T, Sakai K, Kim YS, Engle D, Campbell F, Palmer D, Ko JH, Tuveson DA, Hirsch E, Mielgo A, Schmid MC. Macrophage-secreted granulin supports pancreatic cancer metastasis by inducing liver fibrosis. Nat Cell Biol. 2016; 18:549-560.

22. Geissmann F, Manz MG, Jung S, Sieweke MH, Merad M, Ley K. Development of monocytes, macrophages, and dendritic cells. Science. 2010; 327:656-661.

23. Dey A, Allen J, Hankey-Giblin PA. Ontogeny and polarization of macrophages in inflammation: blood monocytes versus tissue macrophages. Front Immunol. 2015;5:1-15.

24. Friedman SL. Hepatic stellate cells:protean, multifunctional, and enigmatic cells of the liver. Physiol Rev. 2008; 88:125-172.

25. Gressner AM, Bachem MG. Molecular mechanisms of liver fibrogenesis--a homage to the role of activated fat-storing cells. Digestion. 1995;56:335-346.

26. Yamamoto M, Kikuchi H, Ohta M, Kawabata T, Hiramatsu Y, Kondo K, Baba M, Kamiya K, Tanaka T, Kitagawa M, Konno H. TSU68 prevents liver metastasis of colon cancer xenografts by modulating the premetastaticniche. Cancer Res.2008; 68:9754-9762.

27. Wen SW, Sceneay J, Lima LG, Wong CS, Becker M, Krumeich S, Lobb RJ, Castillo V, Wong KN, Ellis S, Parker BS, Möller A. The Biodistribution and Immune Suppressive Effects of Breast Cancer-Derived Exosomes. Cancer Res.2016; 76:6816-6827

28. Liang B, Peng P, Chen S, Li L, Zhang M, Cao D, Yang J, Li H, Gui T, Li X, Shen K. Characterization and proteomic analysis of ovarian cancer-derived exosomes. J Proteomics. 2013; 80:171-182.

29. Yi H, Zheng X, Song J, Shen R, Su Y, Lin D. Exosomes mediated pentose phosphate pathway in ovarian cancer metastasis:a proteomics analysis. Int J Clin Exp Pathol.2015; 8:15719-15728.

30. Kimmelman AC. Metabolic Dependencies in RAS-Driven Cancers. Clin Cancer Res.2015; 21:1828-1834.

31. Gottlieb E. p53 guards the metabolic pathway less travelled. Nat Cell Biol. 2011; 13:195-197.

32. Ying H, Kimmelman AC, Lyssiotis CA, Hua S, Chu GC, Fletcher-Sananikone E, Locasale JW, Son J, Zhang H, Coloff JL, Yan H, Wang W, Chen S, Viale A, Zheng H, Paik JH, Lim C, Guimaraes AR, Martin ES, Chang J, Hezel AF, Perry SR, Hu J, Gan B, Xiao Y, Asara JM, Weissleder R, Wang YA, Chin L, Cantley LC, DePinho RA. Oncogenic Kras maintains pancreatic tumors through regulation of anabolic glucose metabolism. Cell.2012; 149:656-6570.

33. Corbett TH, Roberts BJ, Leopold WR, Peckham JC, Wilkoff LJ, Griswold DP Jr, Schabel FM Jr. Induction and chemotherapeutic response of two transplantable ductal adenocarcinomas of the pancreas in C57BL/6 mice. Cancer Res. 1984; 44:717-726

34. Fu X, Guadagni F, Hoffman RM. A metastatic nudemouse model of human pancreatic cancer constructed orthotopically from histologically intact patient specimens. Proc. Natl. Acad. Sci. 1992; 89:5645-5649. 